\title{
1 Circulation of water through a mussel raft: clearance area vs. idealized linear-
}

2 flows

$4 \quad{ }^{1}$ CSIC - Instituto Investigacións Mariñas, Eduardo Cabello 6, E36208 Vigo, Spain.

52 Universidade de Vigo, Departamento de Física Aplicada, Campus Lagoas6 Marcosende, 36310 Vigo, Spain.

7 *Corresponding author; Tel.: +34 986812644, Fax: +34 986813792, email: $8 \quad$ spiedra@uvigo.es

\section{Abstract}

10 This study suggests revision of ecological concepts as food depletions and/or water flow reductions based on idealized linear-flows through the raft. We offer an alternative based in the extension of the clearance area, defined as the area affected by the nonlinear effects produced by the own and surroundings rafts. These conclusions are supported by our results, which indicate that (1) the preferential entry of water through a mussel raft does not occur through the bow, contrary to previously thought and (2) the intra-raft circulation is strongly influenced by the orientation of the raft relative to the background current direction and did not follow a defined pattern. Intra-raft circulation was assessed by means of four current-meters installed at each side of the raft and the dimensions of the clearance area using long-term data provided by GPS and compass. While both intra-raft circulation and clearance area dimensions resulted to be mainly controlled by tide, the net water exchange through the raft resulted to be reasonably explained by wind and river discharges.

Keywords: Clearance area; Food depletions; Intra-raft circulation; Mussel raft; Ría de 


\section{INTRODUCTION}

The primary importance of water displacement through sea farms is recognized since long time ago (Incze et al. 1981; Rosenberg \& Loo 1983; Wildish \& Kristmanson 1985). Studies describing the feeding behaviour of different organisms in suspended cultures based on empirical relationships between physiological processes and flows are also abundant (Hawkins et al. 1999; Karayücel \& Karayücel 2000; Pouvreau et al. 2000; Sasikumar \& Krishnakumar 2011). Knowledge of water flows through farms is essential to determine important ecological parameters in aquaculture, such us carrying capacity, food availability, food depletion or flow reduction by dragging effects. Despite its importance, circulation within the rafts is a mistreated issue in aquaculture research (Grant \& Bacher 2001). To the best of our knowledge, there are only four publications dealing with currents through rafts based on empirical data (Blanco et al. 1996; Boyd \& Heasman 1998; Riethmüller et al. 2006; Petersen et al. 2008) and another one based on a numerical model (Grant \& Bacher 2001). Most of the previous studies have assumed that mussel rafts face permanently the direction of the current (Fraga \& Vives 1960; Navarro et al. 1991; Cranford et al. 2014) or suggest the need for more precise methods (Blanco et al. 1996; Piedracoba et al. 2014). Although significant efforts have been made on numerical modelling, O’Donncha et al. (2013) assert on the urgent need for a comprehensive field-monitoring program quantifying the effects of an aquaculture installation within a bay to permit the validation of these models in a realistic situation.

The Galician rías are ideal places for the extensive culture of the blue mussel Mytilus galloprovincialis on hanging ropes (Figueiras et al. 2002; Álvarez-Salgado et al. 2011). About 250,000 tons of mussels are extracted from these embayments every year, representing $40 \%$ of the European and $15 \%$ of the World production (Labarta et al. 2004). Our study focuses on the Ría de Ares-Betanzos (Fig. 1), which holds 147 rafts 
51 producing about 10,000 tons of mussels per year (Álvarez-Salgado et al. 2011). These

52 rafts are made from eucalyptus trusses attached to floats and anchored with iron chains 53 to concrete blocks on the sea bed. Since 1990, the characteristics of the rafts are 54 regulated by the local government: each platform contains up to 500 ropes no longer 55 than 12 meters, it has a maximum surface area of about 500 square meters $(20 \mathrm{~m} \times 25$ $56 \mathrm{~m}$ ), and it is separated about $100 \mathrm{~m}$ from the other rafts (Pérez Camacho et al. 1991). 57 Most of the rafts are anchored by an iron chain at the bow, but in the Ría de Vigo (see 58 Fig. 1) they are anchored with a bow and a stern chain. If mussel rafts are anchored by the bow and the stern, the determination of the water flow using four current meters, one per side, is relatively simple because the platform remains fixed. However most

61 rafts in the Galician rías are fixed by one point, which allows the rafts to rotate freely 62 and to translate from its initial position. This fact complicates the determination of 63 water flows through mussel rafts because they can enter these platforms by their four 64 sides.

65 In our case, the raft was equipped with a GPS and a compass and the currents were monitored in the four sides of the raft for several months. The GPS and the compass are

67 essential to characterize the position and rotational movement of the raft and to assess 68 the preferential directions of the water flow through the raft. If these instruments are not 69 installed, the raft cannot be positioned in an inertial frame of reference and, 70 consequently, currents entering or leaving each side of the raft cannot be determined 71 correctly. This is the first study of the water flows through these cultivation platforms in which the position and rotation are monitored simultaneously with the current velocities and during seasonally different periods.

74 This paper is divided in two main parts: (1) water flows through the raft and (2) raft 75 displacement. In the first part, we will deal with the spatial variability of the water flows 
(both tidal and subtidal flows) within the raft by investigating the differences in measured currents at the bow, stern, port and starboard sides of a raft during five periods of the year to look into the seasonal variability. Finally we will calculate the net water exchange within the raft for each period and its relationship with coastal winds and river discharges. In the second part, the clearance zone - defined as the area affected by the non-linear effects produced by the own raft- will be calculated from position and orientation time series and will be related to wind and tidal forcing. Moreover, we will determine the preferred side (bow, stern, starboard or port) of water inflow over a period of almost a year.

\section{MATERIALS AND METHODS}

\subsection{Study site}

The Galician coast is at the northern limit of the eastern boundary upwelling system of the North Atlantic. Coastal winds in this area describe a seasonal cycle characterized by upwelling favourable north-easterly winds from March-April to September-October and downwelling favourable south-westerly winds the rest of the year (Wooster et al. 1976; Torres et al. 2003). During the upwelling season, upwelling events occur with a 1-2 weeks periodicity (Alvarez-Salgado et al. 1993). The Ría de Ares-Betanzos is the largest of the six embayments located in the northern Galician coast, between Cape Fisterra and Cape Prior (NW Iberian Peninsula; Fig. 1), with a surface area of $72 \mathrm{~km}^{2}$, a volume of $0.75 \mathrm{~km}^{3}$ and a maximum length of $19 \mathrm{~km}$. It has two main branches: Ares, the estuary of river Eume, and Betanzos, the estuary of river Mandeo. Our study area is located in the southern inner shore of the ría. In the outer part, the two branches converge into a confluence zone that is freely connected to the adjacent shelf through a mouth that is $40 \mathrm{~m}$ deep and $4 \mathrm{~km}$ wide. In fact, the confluence zone can be considered as an extension of the adjacent shelf that is affected by the intensity, persistence and 
101 direction of coastal winds (Bode \& Varela 1998; Villegas-Ríos et al. 2011). There are

102147 rafts; most of reproductive adults are concentrated in the mussel farms of Arnela 103 (40 rafts) and Lorbé (101 rafts; Fig. 1). This study is based on the data collected in a raft 104 located in the middle of the mussel farm of Lorbé (water depth, $15.5 \mathrm{~m}$ ), named P46 $105\left(43.39146^{\circ},-8.28515^{\circ}\right.$; see Fig. 1). Tidal amplitudes in this embayment ranges from $1060.02 \mathrm{~m}$ during neap tides to $4.14 \mathrm{~m}$ during spring tides (Sánchez-Mata et al. 1999).

107

\subsection{Dataset}

The periods, recording intervals, and number of observations of the position and orientation of the raft, and the velocities of currents and winds are summarized in Table 1. Gaps of less than four hours in any of the time series were interpolated linearly. For gaps of more than four hours, the time series were split into subseries. We were able to produce five 24-days long series in which all the measured variables were recorded simultaneously without gaps. These series are long enough to ensure a robust statistical analysis of the effects of the main harmonics of tides (harmonic analysis) and the winds (correlation analysis) on the displacement of the raft.

\section{Raft position (pos)}

The position of raft P46 was determined using a Campbell Scientific GPS with an accuracy of $\pm 2.5 \mathrm{~m}$ placed at the centre of the raft. Latitude and longitude coordinates were transformed into X-Y UTM coordinates (in meters) to calculate the displacement of the raft.

\section{Raft orientation $(\theta)$}


122 A Young meteorological instruments compass with an accuracy of \pm 2 degrees was

123 installed at the centre of raft P46. The compass was geo-referenced with the bow of the 124 raft and provides the position of the bow respect to the North.

\section{Translational and rotational velocities of the raft}

126 Translational velocity was calculated from the position time series, considering the 127 differential of the position related to time, in the $\mathrm{X}$-axis and in the $\mathrm{Y}$-axis as the $\mathrm{u}$ and $\mathrm{v}$ 128 velocity components, respectively. Concerning the orientation time series, the rotational 129 velocity was calculated as the differential of a rotation movement decomposed into X130 component, $\omega_{\mathrm{x}}=\mathrm{r} \cdot \sin (\Theta)$, and $\mathrm{Y}$-component, $\omega_{\mathrm{y}}=\mathrm{r} \cdot \cos (\Theta)$, where $\mathrm{r}$ is the equivalent 131 radius of a $20 \mathrm{~m} \times 25 \mathrm{~m}$ raft (considering the raft as a circle, i.e. $11 \mathrm{~m}$ ) and $\Theta$ is the 132 orientation angle. The Fast Fourier Transform (FFT) of translational and rotational 133 velocities was calculated for the five series. FFT is a useful tool that converts the time 134 (or space) domain to frequency domain and vice versa. In this study it is useful to 135 identify the energy and related frequencies involved in the translational and rotational 136 movements.

\section{Current direction $(\alpha)$}

138 Four FSI 2D-ACM point current meters with accuracy of $\pm 1 \mathrm{cms}^{-1}$ were hung 139 simultaneously at $1 \mathrm{~m}$ depth at the centre of the four sides (bow, port, starboard and 140 stern) of raft P46. The current meters were attached at two points to maintain a constant 141 orientation with the raft. These instruments are equipped with an internal compass. The 142 angle measured by the compasses, $\alpha$, stores the direction of the current at the side of the 143 raft where each instrument was hung with respect to the true North.

\section{Direction of the water flow entering the $\operatorname{raft}(\delta)$}


145 One main objective of this work is to find out the direction of the water flow through

146 the mussel raft. This direction is given by the angle $\delta$, defined as the angle from the side

147 of raft to the current, counter-clockwise and that is calculated as, $\delta=\theta-\alpha$, where $\Theta$, is

148 the angle derived from the compass (raft orientation time series) and $\alpha$ is the angle of

149 the current measured at each side of the raft respect to the North. The sign of $\sin \delta$

150 indicates if the flow is outgoing $(>0)$ or incoming $(<0)$. We have only measured the

151 orientation of the bow of the raft; for the other sides we have calculated the orientation

152 as follows: $\Theta_{\text {starboard }}=\Theta_{\text {bow }}+90^{\circ} ; \Theta_{\text {stern }}=\Theta_{\text {bow }}+180^{\circ}$; and $\Theta_{\text {port }}=\Theta_{\text {bow }}+270^{\circ}$.

\section{Inertial currents time series}

154 Current time series in each side of the raft were transformed into an inertial reference

155 frame (which is supposed to be zero motion) using the previous defined angle $\delta$.

156 Subtidal flows in the new reference systemwere obtained by applying a $\mathrm{A} 24^{2} \mathrm{~A} 25$ filter

157 with a cut-off period of 30 hours (Godin 1972) to the raw inertial time series to remove

158 the variability at tidal or higher frequencies, which helps to avoid the aliasing errors

159 (Emery \& Thompson 2001). The inertial time series of subtidal velocity for the five

160 studied periods (for details, please see Table 1) are presented in Appendix I.

161 Perpendicular velocities to each side of the raft (fluxes, from here on) were calculated

162 projecting the velocity measured at each side, over its perpendicular axis.

\section{Winds time series}

164 Shelf winds were obtained from the Seawatch buoy of the Spanish Agency Puertos del 165 Estado off Cape Vilano (http:// www.puertos.es) and local winds from a Campbell 166 anemometer installed at the centre of raft P46. Wind time series were low pass filtered 167 to remove the variability at frequencies lower than 30 hoursby applying a $\mathrm{A} 24^{2} \mathrm{~A} 25$ filter(Godin 1972)to the raw time series. Wind time series were also decimated to daily values to perform the correlations with environmental conditions (see section 2.3). 
170 River discharge

171 The flow of river Mandeo, $\mathrm{Q}_{\mathrm{M}}$, was taken from gauge station $\mathrm{n}^{\mathrm{o}} 464$ at Irixoa, 172 administered by the Galician Agency Augas de Galicia. The Horton's Law (Strahler \& 173 Strahler 2007) was applied to estimate flow at the river mouth (total drainage basin: $174456.97 \mathrm{~km}^{2}$ ) from the flow at the gauge station (gauged drainage basin: $248.21 \mathrm{~km}^{2}$ ). 175 The flow of the river Eume, $\mathrm{Q}_{\mathrm{E}}$, is a combination of regulated and natural flows. Daily 176 volumes of the Eume reservoir, which controls $80 \%$ of its drainage basin, were provided 177 by the managing company ENDESA S.A. Assuming that the retention constant for the drainage basin of the river Eume is the same as for the river Mandeo, the natural component of the flow of the river Eume was calculated again from the Horton's Law considering the area not controlled by the reservoir $\left(96.04 \mathrm{~km}^{2}\right)$. Both time series have a daily sampling interval.

\subsection{Analysis of the tidal and wind forcing}

The effect of the tide on the position of the mussel raft will be described from the harmonic analysis of the times series of position $\left(\operatorname{pos}_{\mathrm{x}}, \operatorname{pos}_{\mathrm{y}}\right)$ and orientation $\left(\theta_{\mathrm{x}}, \theta_{\mathrm{y}}\right)$ of the raft. T_tide, an open source MATLAB ${ }^{\circledR}$ toolbox produced by (Pawlowicz et al. 2002), was run to objectively separate out the tidal from the non-tidal components of the position and the orientation time series. Only tidal constituents with significant amplitudes and signal to noise ratios $(\mathrm{SNR})>2$ were chosen.

The relation between wind forcing and the position and orientation of the raft was assessed by performing complex cross-correlations analyses (Kundu \& Allen 1976) between wind and the residuals of the tide obtained from position/orientation time series. Correlations between shelf and local wind were also performed. The complex cross-correlation analysis is a statistical parameter that allows to calculate the 
195

196

197

198

199

200

201

202

203

204

205

206

207

208

209

210

211

212

213

214

215

216

218

219

out of phase (or not) with a time lag. Results show the time lag corresponding to the maximum correlation and the angle between the two time series at the maximum correlation.

Regarding flows, we also assessed the implications of both tide and environment in the intra-raft circulation. Tidal circulation at the raft was described by applying the T_tide code (Pawlowicz et al. 2002) to the raw inertial time series at the four sides of the raft and for the five periods. Intra-raft subtidal circulation was evaluated by means of complex-cross correlations between the subtidal flows at the four sides of the raft during the five periods. Relationships between environment and subtidal circulation were then established by performing complex-cross correlations between the net water balance at the raft (sum of fluxes at each side of the raft) and winds/river discharges. In order to perform the complex cross correlations with the wind, net water transport is assumed to be as $0+\mathrm{i}^{*} \mathrm{Ty}(\mathrm{T}<0$ : inflows; $\mathrm{T}>0$ : outflows). The river discharge was also considered in the same complex form to perform the corresponded correlations with the net transport.

\section{RESULTS}

\subsection{Water flows through the raft}

Direction of the water flow entering the raft

On basis of the time series of $\delta$ (angle formed by the current with each side of the mussel raft; section 2.2) obtained for the four sides of the raft, we have represented the directions of the water flow at each side of the raft in Figure 2. Inflow was more frequent than outflow at all sides, except the bow (inflow: 45\% and outflow: 55\%). The largest difference between inflow and outflow was produced at starboard $(70 \%$ and $30 \%$, respectively), followed by stern and port ( $\sim 60 \%$ vs. $\sim 40 \%)$. At the bow, the occurrence of water outflow through the second quadrant (29\%) was slightly higher than through the first quadrant (26\%). The differences of occurrence of inflow through 
the third $(23 \%)$ and fourth $(22 \%)$ quadrants were negligible. At the stern side, inflow was equally probable through the third (31\%) and fourth (30\%) quadrants and outflow was slightly more probable through the first $(21 \%)$ than through the second $(18 \%)$ quadrant. Inflow and outflow was quite homogeneous through the port side (outflow: $21 \%$ and 20\%; inflow: $29 \%$ and $30 \%$ ). At the starboard side, $41 \%$ of the time the water flows into the third quadrant and only $15 \%$ of the time flows out through the first quadrant.

\section{Intra-raft circulation}

The intra-raft circulation has been studied by assessing the similarities and differences of the time-series of inertial flows through the four sides of the raft considering two different time scales: tidal and subtidal.

Tidal intra-raft circulation was evaluated by means of applying harmonic analysis (see section 2.3) to the five time series of raw inertial velocities at the four sides of the raft. The results for each series are summarised in Table 2. Tide is assumed as the contribution of the constituents with significant amplitudes and signal to noise ratios $>2$. We present only the results for the most important harmonic, $\mathrm{M}_{2}$ (Piedracoba et al. 2014). During all the periods, the tide explained more variability at the starboard side $(56 \%, 54 \%, 27 \%, 59 \%$ and 14\%, for Jul-10, Aug-10, Mar-11, Apr-11 and May-11, respectively) than at the other three sides. The stern and the port were the sides where tide explained the lowest percentages of variability, except during Aug-10 when tide explained more than $19 \%$ of the variability of the flows at all sides. The highest $\mathrm{M}_{2}$ intensities were found at starboard (between 2.5 and $7.9 \mathrm{~cm} \mathrm{~s}^{-1}$ depending on the period) and the lowest at stern and the port (between 0.5 and $1.3 \mathrm{~cm} \mathrm{~s}^{-1}$ ).

Subtidal intra-raft circulation was assessed by performing complex-cross correlations (Kundu \& Allen 1976) between inertial subtidal flows at each side of the raft (Appendix 
245 I) and for the five periods. Results are summarised in Table 3. There were no significant 246 differences in correlation coefficients at different lag-times in all cases. The maximum 247 correlation occurred at $0 \mathrm{~h}$ lag time. There was not a common pattern of subtidal 248 circulation among the four sides of the raft. During Jul-10 and Mar-10 (periods 1, 3), 249 the subtidal circulation at the bow side reached the best coupling with the starboard side $250(\mathrm{R}=0.92$ and $\mathrm{R}=0.62$, respectively $)$ when the angle between currents was of $\mathrm{Ph}=197^{\circ}$ and $\mathrm{Ph}=119^{\circ}$, respectively. This fact implies that the currents are actually perpendicular to each other as the reference system of two consecutives sides of the raft has a 90 degree angle between them. During Aug-10 (period 2), the best correlation was between bow and port $(\mathrm{R}=0.81)$ and the angle between currents was similar to the previous case $\left(\mathrm{Ph}=134^{\circ}\right)$. For the last two periods (Apr-11 and May-11), the highest correlation was achieved between stern and starboard $(\mathrm{R}=0.59$ and $\mathrm{R}=0.49$, respectively) with also similar directions $\left(\mathrm{Ph}=131^{\circ}\right.$ and $\mathrm{Ph}=162^{\circ}$, respectively). In general, all sides are wellcorrelated between them. The starboard side was always (except during period 2) implied in the highest correlations (with the bow side during periods 1 and 3 and with the stern side during periods 4 and 5).

\subsection{Water budgets of the raft}

\section{Fluxes through each side of the raft}

Perpendicular velocities (both subtidal and raw velocities) through each side of the raft were used to obtain the fluxes across the raft. In Figure 3, we present a sketch of the subtidal fluxes at each side of the raft and the most probable orientation of the raft during each of the five studied periods. During Jul-10 and Aug-10 (Figs. 3a and 3b), inflow (in percentage) was dominant at all sides except at the bow. The water flows into the raft through all sides, and the bow acts as a spillway. Maximum P50 (the $50^{\text {th }}$ percentile) velocities were registered in the inflow through the port and starboard $(\sim 1.5$ 
$270 \mathrm{~cm} \mathrm{~s}^{-1}$ ). During Mar-11 (Fig.3c), inflow was more frequent than outflow at the 271 starboard and stern ( $98 \%$ vs $2 \%$ and $79 \%$ vs $21 \%$, respectively) while port acts now as 272 the main exit of water flow ( $34 \%$ vs $66 \%$ ). The bow is in equilibrium (51\% vs. $49 \%$ ).

273 Maximum P50 velocities were achieved also at starboard but now with more intensity $274\left(3.3 \mathrm{~cm} \mathrm{~s}^{-1}\right)$. The maximum P50 velocities were also registered in the inflow at 275 starboard (4.1 $\mathrm{cm} \mathrm{s}^{-1}$ ), during Apr-11 (Fig.3d). Moreover inflow occurred $100 \%$ of the 276 time at this side. The other three sides acted as exits under this condition. Finally, 277 during May-11 (Fig. 3e), the starboard behaves in the same way as during the two 278 previous cases (more inflow than outflow and high velocity). In this case, the port also 279 acted mainly as an input while the stern registered most of outflow. There is equilibrium 280 between inflows and outflows at the bow.

281 The only side that did not change its behaviour over the 5 periods was the starboard and 282 it was also the side where maximum P50 velocities were registered. The orientation of 283 the rafts was towards the South-East for all periods (as the general behaviour previously 284 described) except during May-11, when the main orientation of the bow was towards 285 the South-West.

Net water transport

287 Time series of the net water volume transported inside/outside the raft in the first meter of the water column were obtained as the sum of the transport at each side of the raft at each time. The transport at each side was obtained assuming lateral homogeneity along the sides of the raft and multiplying each value of the instantaneous velocity times and the width of each side of the raft $(20 \mathrm{~m}$ width for bow and stern and $25 \mathrm{~m}$ for starboard and port sides). The net transport is obtained in volume per unit of time. The time series of the net water volume transported inside/outside (negative/positive values) the raft 
295 specific moments the net transport is outwards the raft (Fig.4b: period 2; from 09-14

296 Aug and Fig. 4e: period 5; 06 May). The maximum volume transported inside the raft is 297 produced during the first days of the period 3 (Mar-11). There are also moments during 298 periods 4 and 5 when the transport almost achieved this maximum value of transport 299 inwards the raft (23 Apr and 19-May). In general, the 24-day averaged $\pm \mathrm{SD}$ transport 300 was negative for all periods, being considerably lower (in absolute terms) during July and August $2010\left(-5000 \pm 2800\right.$ and $-3700 \pm 4100 \mathrm{~m}^{3} \mathrm{~s}^{-1}$, respectively) than during the other three periods $\left(-9000 \pm 3800 \mathrm{~m}^{3} \mathrm{~s}^{-1},-8500 \pm 3600 \mathrm{~m}^{3} \mathrm{~s}^{-1}\right.$, and $-8900 \pm 4500 \mathrm{~m}^{3} \mathrm{~s}^{-1}$, respectively).

Previous calculations (fluxes and net water transport) were also made using raw velocities to assess any asymmetry produced by tidal circulation. Both results were coincident, evidencing that tide is a stationary forcing and that it does not cause any imbalance between the flooding and ebbing flows within the raft.

Environment and their relationship with the net water transport

Coastal winds and river discharge were used to describe the environmental conditions acting within the ría during the five studied periods (Fig.5). During Jul-10 and Aug-10 (Figs. 5a, b), the river discharge was lower than in the other periods. The main difference between both periods was the wind regime: while during Jul-10 shelf winds blew alternatively from the NE and SW, during Aug-10 they were mainly northerly. During Mar-11 and Apr-11 (Figs. 5c, d), freshwater inputs were higher than during the summer. Mar-11 was mainly characterized by weak SW winds. During Apr-11 winds were stronger and mainly from North but were more variable and much less intense than during Aug-10. Finally, during May-11 the river flow decreased and winds blew with more intensity and mainly from the NE. 
319 The time series of the net water volume transported inside/outside (negative/positive

320 values) the raft were related with shelf winds and river discharge by complex cross 321 correlations (Table 4). The time lag for maximum correlations was close to $0 \mathrm{~h}$ for both 322 variables, which implies that the effects of winds and river discharge in the net water 323 transport are produced within less than a day. Results show that the net water transport 324 is related with the wind, especially during the periods with northerly winds (Aug-10: 325 0.79, Apr-11: 0.72 and May-11: 0.71). During March-11, characterized mainly by 326 southerly winds, the correlation was not significant. The phases show that both vectors 327 follow the same direction $\left(318^{\circ}<\mathrm{Ph}<338^{\circ}\right.$, for all the correlations), which suggest that 328 northerly $(\mathrm{Wy}<0) /$ southerly winds $(\mathrm{Wy}>0)$ contribute to net water volume inwards $329(\mathrm{Ty}<0) /$ outwards $(\mathrm{Ty}>0)$ the raft.

330 Regarding river discharge, correlations were significant for all the periods. The highest 331 (lowest) correlation coefficient was obtained during April-11, $\mathrm{R}=0.94$ (Aug-10, $332 \mathrm{R}=0.67)$. The phase between both vectors is $180^{\circ}$, for all the cases, which implies that increases/decreases in river discharges contribute to increase net water volume inwards $334(\mathrm{Ty}<0) /$ outwards $($ Ty $>0)$ the raft.

335 Consistently with cross correlations results, the few times during which net transport is 336 outwards (Fig. 4b: 11-Aug and Fig. 4e: 06-May) are coincident with absence of 337 northerly winds and low river discharge (Fig. 5b: 11-Aug) or with southerly winds (Fig. 338 5e: 6-May). Situations of southerly winds with high river discharge (Fig. 5c: 25-Mar) 339 decrease the transport inwards of the raft but the net transport does not become positive 340 (outwards of the raft) (Fig. 4c: 25-Mar). This last fact, with the high coefficients of 341 river-transport correlations in comparison with the ones obtained in the wind-transport 342 correlations, suggest that the influence of river discharge is stronger than the one 343 induced by the winds. 
344

345

346

347

348

349

350

351

352

353

354

355

356

357

358

359

360

361

362

363

364

365

366

367

368

\subsection{Clearance zone}

\section{Displacement of the mussel raft: translation and rotation}

The translational and rotational displacements of a raft anchored by the bow throw light on the extension and shape of the volume cleared by the filtration activity of the hanging mussels. Whereas the translation of the raft is limited by the chain length, it has the ability to freely rotate $360^{\circ}$.

The clearance zone was calculated from the time series of the position of raft P46 (Fig. 6). Positive/negative values denote distance in meters from the theoretical position of the bow of raft at the vertical of the anchor position $\left(43.39146^{\circ}, 8.28515^{\circ}\right)$ towards East/West (x-axis) and North/South (y-axis). The most probable position of the bow of the raft $(8 \%$ of the time $)$ was $(-5,5)$, i.e. $5 \mathrm{~m}$ towards the West and $5 \mathrm{~m}$ towards the North. The raft displaced basically along the NW-SE axis. Figure 6 also shows the accumulated probabilities in the $x-$ and $y$-axis. Most of the time $(>60 \%)$, the raft was confined within $5 \mathrm{~m}$ towards the East and West and 10 meters towards the North and South.

Concerning rotation, the raft was $20 \%$ of the time with the bow oriented between $90^{\circ}$ and $135^{\circ}$ and another $20 \%$ of the time between $237.5^{\circ}$ and $282.5^{\circ}$ (Fig. 7). The orientation of the raft with the bow towards the North was almost negligible.

\section{Translational and rotational velocities of the raft}

We calculated the velocity of translation and rotation of the mussel raft to assess whether it would be necessary to subtract these displacements to the current meter records to calculate the water flow at each side of the raft. In Table 5, we report a comparison, for each period, between the velocities of the raft (translational and rotational) and the magnitude of the raw velocity recorded at each side of the raft. Note that the displacement of the raft in comparison with the flow that enters or leaves the 
369

370

371

372

373

374

375

raft at any of their four sides is negligible. For all periods, $50 \%$ of the translational (rotational) velocities are contained within the $[0.14,0.54] \mathrm{cm} \mathrm{s}^{-1}\left([0.06,0.35] \mathrm{cm} \mathrm{s}^{-1}\right)$ interval, while $50 \%$ of the flows at any of the sides of the raft were about an order of magnitude larger.

The spectral analysis of translational and rotational velocities (Appendix II) showed counter-clockwise (CCW) semi-diurnal ( $\sim 12 \mathrm{~h})$ energy peaks, except for the last period. However, clockwise $(\mathrm{CW})$ peaks did not appear in any of the study periods. Note that although the raft might randomly spin $\mathrm{CW}$ or $\mathrm{CCW}$ at slack water, our results indicate that it always spins $\mathrm{CCW}$ and the displacement is always along the same direction.

\section{Forcing agents: tide and wind regimes}

The analysis of the effect of the tide on raft P46 was based on a harmonic tidal analysis of the five 24-days long time series of the position (pos) and the orientation angle $(\theta)$ (Table 5). The results of these analyses were similar for both variables. The percentage of the total variability explained by the tide was $>50 \%$, except for the last period (May11), when the explained variability reduced to $19.4 \%$ and $21.8 \%$ for position and orientation, respectively. The tidal signals obtained from the position time series (Appendix III) coincided, both in extension and shape, with the clearance zone previously described in Figure 6. Therefore, the translation of the raft was mainly due to the tide. The clearance zone occupied by the tidal signal obtained from the position time series was quite similar for the 5 periods, except for the last one, when the tide explained the lowest portion of the variability (19.4\%; Table 5). The shape of the tidal signal obtained from the orientation time series (Appendix III) was also very similar to the predominant directions of rotation of the raft (Fig. 7). Both the position and orientation tidal signals (only those obtained for period 1 for clarity) were superimposed 
393

on the clearance zone of Figure 6 . The clearance zone of the raft was in agreement with the tidal signal obtained from both harmonic analyses.

The rose of shelf winds (Fig. 8a) shows that the predominant direction was along the NE-SW axis. North-Easterly winds were much more common (49\% of the time) than South-Westerly winds (29\% of the time) during the study period. Local wind (Fig. 8b) patterns were similar to shelf winds but the frequency difference between NE and SW local winds was lower: $33 \%$ versus $29 \%$ of the time, respectively. The SE component of the wind was more frequent into the ría than over the shelf: $20 \%$ vs. $6 \%$ of the time and the NW component remained almost constant for both winds (16\% and $18 \%$ of the time for shelf and local winds, respectively). Note that wind intensities over the shelf were more than twice those inside the ría (Fig. 4c).

Complex cross-correlations analyses were performed between subtidal shelf and local winds (Table 5) showing high regression coefficients between them. Maximum correlation coefficients between remote and local wind time-series were obtained at time lag of $0 \mathrm{~h}$ for all periods and when both winds formed an angle smaller than $15^{\circ}$. Complex cross-correlations were also performed between the residuals of the tide (obtained by subtracting the predicted tide from the original time series) and subtidal shelf and local winds for the five periods. On basis of the $\sigma_{\text {res }} / \varepsilon_{\text {instr }}$ ratio, where $\sigma_{\text {res }}$ is the standard deviation of the residual time seriesand $\varepsilon_{\text {instr }}$ is the instrumental error $\left(\varepsilon_{\mathrm{GPS}}=\right.$ $\pm 2.5 \mathrm{~m}$ and $\left.\varepsilon_{\text {Compass }}= \pm 2^{\circ}(\sim 22 \mathrm{~m})\right)$, the most reliable correlation analysis was obtained with the position time series. The maximum correlation coefficients were obtained around the time lag of $0 \mathrm{~h}$ for all the comparisons. For position time series, periods 2 and 5 showed the highest correlation coefficients $(R=0.63$ and 0.58 , for local winds and $\mathrm{R}=0.60$ and 0.56 for shelf winds, for periods 2 and 5 , respectively). During period 3 correlations were not significant. During period 2, the maximum correlation is 
418 produced when the angle between the wind and the displacement of the raft is about $70^{\circ}$

$419(\mathrm{CCW})$. However, during period 5, the maximum correlation is produced when the wind 420 and the displacement of the raft are almost opposite $\left(\sim 200^{\circ} \mathrm{CCW}\right)$.

421 Regarding the orientation time series, periods 2 and 5 also showed the highest 422 correlation coefficients $(\mathrm{R}=0.69$ and 0.69 , for local winds and $\mathrm{R}=0.67$ and 0.62 for

423 shelf winds, for periods 2 and 5, respectively). Winds and rotational displacement of the 424 raft are in phase $\left(318^{\circ} \leq \mathrm{Ph} \leq 9^{\circ}\right)$ for all the periods. The lowest significant correlation 425 was obtained for the first period ( $\mathrm{R}=0.33$ for local winds). Concerning shelf winds, 426 only correlations during periods 2 and 5 were significant.

\section{4. DISCUSSION}

\section{$428 \quad$ 4.1. Flows through raft}

429 Our results indicate that water inflow (outflow) does not take place through the bow 430 (stern) of the rafts, as often considered. In general, in rafts anchored with only one 431 chain, water enters/exits the platform by all sides, although with different frequencies. 432 In the particular case of raft P46 of the Ria de Ares-Betanzos, the starboard side resulted 433 to be the most exposed to water inflow. Moreover, the general pattern that we observed confirmed that at all sides, except the bow, inflow is larger than outflow and that starboard was the side of the raft where differences between inflow and outflow were more evident.

437 The intra-raft circulation was very complex and did not follow a defined pattern. We 438 hypothesized that it is strongly influenced by the orientation and position of the raft 439 relative to the background current direction. (Boyd \& Heasman 1998)) also found that 440 the intra-raft circulation depended on the angle between ambient flow and the physical 441 raft axis and found evidences of near-surface flow divergences around their raft. 
442 Stevens and Petersen (2011) also pointed out that the response of the surrounding

443 waters next to a farm was complex and highly variable.

444 We suggested that the preconceived idea of water flowing from one side to the opposite 445 side of the raft must be rebuffed at the cultivation area of Lorbé polygon since it is 446 possible in very specific environmental conditions. Previous works in our area are based 447 on this false premise and, therefore, the existing estimation of both ecological 448 parameters (e.g. food depletions) and hydrodynamic parameters (e.g. flow reduction), 449 are not realistic. To solve this problem in a raft located in this same ría, Cranford et al. 450 (2014) made the assumption that the rotation of the raft around the anchor point would 451 align the instrument moorings parallel with the current direction such that the raft bow 452 faces into the current. However, the strict criteria for ensuring instrument alignment 453 resulted in $53 \%$ of the sampling periods being excluded from the analysis.

454 From our results, we highly encouraged to make both food depletion and flow reduction 455 calculations comparing both variables outside and inside the clearance zone, 456 respectively, instead of comparing two sides of the raft. In that case, we are also 457 avoiding the physical barrier imposed by aquaculture structures (O’Donncha et al. 2013; 458 Plew, 2011), which can result in a considerable overestimation of nutrient supply to 459 bivalve and, thus, an overestimation of carrying capacity.

\section{4.2. Water budgets at the raft}

461 The net water exchange within the raft can be reasonably explained by wind and river 462 discharges. The interaction between winds and river discharge in this ría is key not only 463 for understanding the hydrodynamics of the embayment (Duarte et al. 2014) but also to 464 quantify the availability and quality of mussel's food (Aguiar et al. submitted). Water 465 net transport through the raft P46 resulted to be mainly in equilibrium during summer 466 months while during the rest of the periods, the net transport resulted negative (inflows 
$467>$ outflows). Correlations between winds, river discharge and the net water transport

468 point out the idea that the water inflows through the raft are helped by northerly winds 469 and large river flows. Results also suggest that in the Ría de Ares-Betanzos, the 470 influence of river discharge is stronger than the one induced by coastal winds, as

471 previously suggested by Álvarez-Salgado et al. (2011) and Duarte et al. (2014).

472 We must be aware that 3D effects, i.e. downward/upward motions within the raft were 473 not considered and they would be necessary to assure compliance with the law of 474 conservation of mass form fluids. Duarte et al. (2014) reported that the Ría de Ares475 Betanzos has a positive circulation during almost all the year. This 2-layer circulation 476 pattern with bottom/surface water inwards/outwards the embayment necessarily implies

477 3D movements. Moreover, the flow also creates divergences around the raft and the 478 assumption of lateral homogeneity of flows along 20 and/or $25 \mathrm{~m}$ sides of the raft could 479 be not true.

\section{$480 \quad 4.3$ Clearance zone}

481 The changes produced at the position of a raft determine the dimensions of the clearance 482 zone, which is a straightforward way to establish the area where non-linear effects such 483 as intra and inter-raft turbulence of the hanging ropes are affecting the local flow. The 484 dimensions of the clearance zone depend largely on, the morphology, bathymetry, 485 freshwater discharge, tidal dynamics and wind regime, besides raft dimensions and 486 length of the anchoring chain.Our results showed that, in the particular case of the Ría 487 de Ares-Betanzos, the clearance zone of raft P46 is controlled mainly by the tide, which explains more than $55 \%$ of the variability in the position of a raft. Moreover, the translational and rotational velocities confirmed that the raft displacement occurs with a 490 periodicity of twice a day. Flood and ebb tidal currents often produce a displacement of 491 the raft along the NW-SE direction (translational movement) and a deterministic 
492 rotation of the raft with two predominant directions (rotational movement). Previous 493 results in this ría (Piedracoba et al. 2014) demonstrated that (1) the eccentricity of the 494 tidal currents (outside the rafts) was close to one, i.e. the tide has not a preferred 495 direction of rotation; and (2) tidal currents tend to accommodate to the shape of the ría, 496 with a mean along-channel orientation for the most important harmonic constituent $\left(\mathrm{M}_{2}\right.$ 497 inclination at Lorbé is $139^{\circ} \pm 8^{\circ}, \mathrm{CCW}$ degrees from East). These results are also in 498 agreement with the orientation of the clearance area. The theoretical clearance zone 499 defined by the length of the anchor chain (35 $\mathrm{m}$ in the case of raft P46) would be a 500 circle with a radius of 28 to $33 \mathrm{~m}$ depending on high or low spring tides, respectively.

501 We must also consider that the real clearance zone has $25 \times 20 \mathrm{~m}$ more of area due to the 502 own raft dimensions (the GPS is positioned at the bow of the raft). Therefore, the 503 theoretical clearance area would be a circle of 48 to $58 \mathrm{~m}$ of radius. However, we have 504 demonstrated here that the shape of the real clearance area is a $139^{\circ} \mathrm{CCW}$ ellipse rather 505 than a circle and that its dimensions are in good agreement with the theoretical results. 506 The $100 \mathrm{~m}$ of separation between rafts established by government seem a conservative 507 but good choice.

508 The tide revealed as an ideal mechanism both to move and to rotate the mussel rafts and 509 to ensure that all the sides of the platform receive their food supply. However, there 510 were periods when the variability of the position explained by the tide was lower than in 511 others. This is because besides the tidal circulation, the circulation inside any 512 embayment is affected by other mechanisms such as wind (Souto et al. 2003; deCastro 513 et al. 2004; Piedracoba et al. 2005; Villegas-Ríos et al. 2011), bathymetry (Lee \& Valle514 Levinson 2012), orientation of the estuaries (Álvarez-Salgado et al. 2011), river 515 discharge (Pritchard 1955; Álvarez-Salgado et al. 2011; Duarte et al. 2014) and/or solar 516 heating (Wiles et al. 2006). Although the Ría de Ares-Betanzos is considered as a 
517 tidally dominate estuary (Sánchez-Mata et al. 1999; Piedracoba et al. 2014), particular

518 meteorological episodes can modify and/or inhibit the tidal circulation, e.g. stratification

519 (Howarth 1998, Palmer 2010) and/or wind (deCastro et al. 2000).

520 From the view point of the mussel raft culture, the advantage of a tidally dominated

521 estuary is that it would lead to a homogenization of the harvest sizes distributions of

522 mussels within the four sides of the raft. This fact is a basic issue for mussel farmers

523 (Cubillo et al. 2012) and is the tendency in this embayment when compared with the

524 Ría de Arousa (placed South, see Fig. 1), where mussels grow faster at the bow of the

525 rafts (Navarro et al. 1991; Fuentes \& Molares 1994; Pérez-Camacho et al. 1995). Both

526 rafts have the same dimensions and the same anchoring system. We hypothesized that

527 the main reason for mussel raft displacement in the Ría de Arousa are the winds rather

528 than the tide. As reported by Álvarez-Salgado et al. (2011) the different orientation of

529 the rías de Arousa and Ares-Betanzos is the likely reason for this difference: wind-

530 driven upwelling in the Ría de Ares-Betanzos was 50\% less frequent and $40 \%$ less

531 intense than in the Rías Baixas (Vigo, Pontevedra, Arousa and Muros).

\section{Conclusions}

533 Water flows through raft P46 of the Ria de Ares-Betanzos indicate that, contrary to 534 previously thought, preferential entry did not occur through the bow of the raft and that 535 the most exposed side to circulation was the starboard. The preconceived idea of water 536 flowing from one to the opposite side of the raft must be rebutted at the cultivation area 537 of Lorbé. Therefore, ecological concepts based on idealized linear-flows through rafts 538 must be revised. We highly encourage using the shape and dimension of the clearance 539 area dimensions instead (outside/within the clearance area). In our case, displacement of 540 the raft was along the NW-SE axis and the orientation of the bow was mainly towards 541 the ESE. The clearance zone was confined within a circle of $50 \mathrm{~m}$ radius and the most 
542 probable position of the bow was $5 \mathrm{~m}$ towards the West and $5 \mathrm{~m}$ towards the North.

543 While both intra-raft circulation and clearance area resulted to be mainly controlled by 544 tide, the net water exchange through the raft resulted to be reasonably explained by 545 wind and river discharges.

546 Acknowledgements

547 We wish to thank PROINSA Mussel Farm and their employees, especially H.Regueiro 548 and M. García for technical assistance. This study was supported by PROINSA-CSIC contract-project (CSIC0704101100001), and MICINN ESSMA project (ACI2008-0780)

\section{References}

Aguiar E, Fuentes-Santos I, Labarta U, Álvarez-Salgado XA, Fernández-Reiriz MJ Empirical modelling of seston food quality based on environmental factors in a mussel culture area (NW Iberian upwelling system). submitted

Álvarez-Salgado XA, Figueiras FG, Fernández-Reiriz MJ, Labarta U, Peteiro L, Piedracoba S (2011) Control of lipophilic shellfish poisoning outbreaks by seasonal upwelling and continental runoff. Harmful Algae 10:121-129

Alvarez-Salgado XA, Rosón G, Pérez FF, Pazos Y (1993) Hydrographic variability off the Rías Baixas (NW Spain) during the upwelling season. J Geophys Res 98:14447-14,455

Blanco J, Zapata M, Moroño Á (1996) Some aspects of the water flow through mussel rafts. Scientia Marina 60:275-282

Bode A, Varela M (1998) Primary production and phytoplankton in three Galician Rías Altas (NW Spain): seasonal and spatial variability. Scientia Marina 62:319-330

Boyd AJ, Heasman KG (1998) Shellfish mariculture in the Benguela system: Water flow patterns within a mussel farm in Saldanha Bay, South Africa. :25-32

Cranford PJ, Duarte P, Robinson SMC, Fernández-Reiriz MJ, Labarta U (2014) Suspended particulate matter depletion and flow modification inside mussel (Mytilus galloprovincialis) culture rafts in the Ría de Betanzos, Spain. Journal of Experimental Marine Biology and Ecology 452:70-81

Cubillo AM, Peteiro LG, Fernández-Reiriz MJ, Labarta U (2012) Influence of stocking density on growth of mussels (Mytilus galloprovincialis) in suspended culture. Aquaculture 342-343:103-111 
deCastro M, Gomez-Gesteira M, Prego R, Alvarez I (2004) Ria-ocean exchange driven by tides in the Ria of Ferrol (NW Spain). Estuarine, Coastal and Shelf Science $61: 15-24$

deCastro M, Gómez-Gesteira M, Prego R, Taboada JJ, Montero P, Herbello P, PérezVillar V (2000) Wind and Tidal Influence on Water Circulation in a Galician Ria (NW Spain). Estuarine, Coastal and Shelf Science 51:161-176

Duarte P, Alvarez-Salgado XA, Fernández-Reiriz MJ, Piedracoba S, Labarta U (2014) A modeling study on the hydrodynamics of a coastal embayment occupied by mussel farms (Ria de Ares-Betanzos, NW Iberian Peninsula). Estuarine, Coastal and Shelf Science 147:42-55

Emery WJ, Thompson RE (2001) Data analysis methods in physical oceanography. Elsevier

Figueiras FG, Labarta U, Reiriz MJF (2002) Coastal upwelling, primary production and mussel growth in the Rías Baixas of Galicia. Hydrobiologia 484:121-131

Fraga F, Vives F (1960) Retención de partículas orgánicas por el mejillón en los viveros flotantes. Reunión Prod Mar ExplotPesq:51-71

Fuentes J, Molares J (1994) Settlement of the mussel Mytilus galloprovincialis on collectors suspended from rafts in the Ría de Arousa (NW of Spain): annual pattern and spatial variability. Aquaculture 122:55-62

Godin G (1972) The analysis of tides. University of Toronto:264

Grant J, Bacher C (2001) A numerical model of flow modification induced by suspended aquaculture in a Chinese bay. Canadian Journal of Fisheries and Aquatic Sciences 58:1003-1011

Hawkins AJS, R. J M, Hickman, R. W., Hatton, S., Weatherhead, M. (1999) Modelling of suspension-feeding and growth in the green-lipped mussel Perna canaliculus exposed to natural and experimental variations of seston availability in the Marlborough Sounds, New Zealand. Mar Ecol, Prog Ser 191:217-232

Howarth MJ (1998) The effect of stratification on tidal current profiles. Continental Shelf Research 18:1235-1254

Incze LS, Lutz RA, True E (1981) Modeling Carrying Capacities for Bivalve Molluscs in Open, Suspended-Culture Systems. Journal of the World Mariculture Society $12: 141-155$

Karayücel S, Karayücel İ (2000) The effect of environmental factors, depth and position on the growth and mortality of raft-cultured blue mussels (Mytilus edulis L.). Aquaculture Research 31:893-899

Kundu PK, Allen JS (1976) Some Three-Dimensional Characteristics of LowFrequency Current Fluctuations near the Oregon Coast. Journal of Physical Oceanography 6:181-199 
Labarta U, Fernández-Reiriz, Pérez-Camacho, Alejandro, Pérez-Corbacho, E. (2004) Bateeiros, mar, mejillón. Una perspectiva bioeconómica. Fundación Caixa Galicia., A Coruña, Spain

Lee J, Valle-Levinson A (2012) Influence of bathymetry on hydrography and circulation at the region between an estuary mouth and the adjacent continental shelf. Continental Shelf Research 41:77-91

Navarro E, Iglesias JIP, Perez Camacho A, Labarta U, Beiras R (1991) The physiological energetics of mussels (Mytilus galloprovincialis Lmk) from different cultivation rafts in the Ria de Arosa (Galicia, N.W. Spain). Aquaculture 94:197-212

O'Donncha F, Hartnett M, Nash S (2013) Physical and numerical investigation of the hydrodynamic implications of aquaculture farms. Aquacultural Engineering 52:14-26

Palmer MR (2010) The modification of current ellipses by stratification in the Liverpool Bay ROFI. Ocean Dynamics 60:219-226

Pawlowicz R, Beardsley B, Lentz S (2002) Classical tidal harmonic analysis including error estimates in MATLAB using T_TIDE. Computers \& Geosciences 28:929937

Pérez Camacho A, González R, Fuentes J (1991) Mussel culture in Galicia (N.W. Spain). Aquaculture 94:263-278

Pérez-Camacho A, Labarta U, Beiras R (1995) Growth of mussels (Mytilus edulis galloprovincialis) on cultivation rafts: influence of seed source, cultivation site and phytoplankton availability. Aquaculture 138:349-362

Petersen J, Nielsen T, Duren L van, Maar M (2008) Depletion of plankton in a raft culture of Mytilus galloprovincialis in Ría de Vigo, NW Spain. I. Phytoplankton. :113-125

Piedracoba S, Álvarez-Salgado XA, Labarta U, Fernández-Reiriz MJ, Gómez B, Balseiro C (2014) Water flows through mussel rafts and their relationship with wind speed in a coastal embayment (Ría de Ares-Betanzos, NW Spain). Continental Shelf Research 75:1-14

Piedracoba S, Álvarez-Salgado XA, Rosón G, Herrera JL (2005) Short-timescale thermohaline variability and residual circulation in the central segment of the coastal upwelling system of the Ría de Vigo (northwest Spain) during four contrasting periods. Journal of Geophysical Research: Oceans 110:C03018

Pouvreau S, Bacher C, Héral M (2000) Ecophysiological model of growth and reproduction of the black pearl oyster, Pinctada margaritifera: potential applications for pearl farming in French Polynesia. Aquaculture 186:117-144

Pritchard DW (1955) Estuarine circulation patterns. Johns Hopkins University, Chesapeake Bay Institute:717-727 
Riethmüller R, Jäger, N., Häse, C., Fernandes, L., Neves, R. (2006) Flow patterns around a within a raft mussel farm in Ría de Vigo, Spain. GKKS, Germany

Rosenberg R, Loo L-O (1983) Energy-flow in a Mytilus edulis culture in western Sweden. Aquaculture 35:151-161

Sánchez-Mata A, Glémarec M, Mora J (1999) Physico-chemical structure of the benthic environment of a Galician ría (Ría de Ares-Betanzos, north-west Spain). Journal of the Marine Biological Association of the United Kingdom 79:1-21

Sasikumar G, Krishnakumar PK (2011) Aquaculture planning for suspended bivalve farming systems: The integration of physiological response of green mussel with environmental variability in site selection. Ecological Indicators 11:734-740

Souto C, Gilcoto M, Fariña-Busto L, Pérez FF (2003) Modeling the residual circulation of a coastal embayment affected by wind-driven upwelling: Circulation of the Ría de Vigo (NW Spain). Journal of geophysical research 108:3340

Stevens C, Petersen J (2011) Turbulent, stratified flow through a suspended shellfish canopy: implications for mussel farm design. Aquaculture Environment Interactions 2:87-104

Strahler A, Strahler A (2007) Physical geography. Wiley, New York

Torres R, Barton ED, Miller P, Fanjul E (2003) Spatial patterns of wind and sea surface temperature in the Galician upwelling region. Journal of Geophysical Research: Oceans 108:3130

Villegas-Ríos D, Álvarez-Salgado XA, Piedracoba S, Rosón G, Labarta U, FernándezReiriz MJ (2011) Net ecosystem metabolism of a coastal embayment fertilised by upwelling and continental runoff. Continental Shelf Research 31:400-413

Wildish DJ, Kristmanson DD (1985) Control of suspension feeding bivalve production by current speed. Helgolander Meeresunters 39:237-243

Wiles PJ, Duren LA van, Häse C, Larsen J, Simpson JH (2006) Stratification and mixing in the Limfjorden in relation to mussel culture. Journal of Marine Systems 60:129-143

Wooster W., Bakun A, McLain DR (1976) The seasonal upwelling cycle along the eastern boundary of the North Atlantic. J mar Res 34:131-141 
Table 1. Starting and ending dates, sampling intervals (f), and number of observations (n) of the time series used in this work: pos, position of the bow of raft P46; $\Theta$, angle of the bow of raft P46 respect to the North; Angles, which contain $\Theta, \alpha_{\text {bow }}, \alpha_{\text {stern }}, \alpha_{\text {port }}, \alpha_{\text {starboard, }}$ and $\delta_{\text {bow }}, \delta_{\text {stern }}, \delta_{\text {port }}, \delta_{\text {starboard, }}$ where $\alpha$ is the angle of the current measured at each side of raft P46 referred to the North; and $\delta$ is the angle between the current and each side of the mussel raft, which is calculated as the difference between $\Theta$ and $\alpha . \% \mathrm{NaNs}$, percentage of invalid data. Subseries, refers to 24-days long series in which all the previous variables (and the magnitude of velocities in each side of the raft) were recorded simultaneously without gaps.

\begin{tabular}{|c|c|c|c|c|c|}
\hline Time series & Start & End & f (min) & $\mathbf{n}$ & $\%$ NaNs \\
\hline Raw series & & & & & \\
\hline pos & $29 / 06 / 201010: 44$ & 14/06/2011 09:44 & 10 & 40967 & 2.3 \\
\hline$\theta$ & $21 / 06 / 201010: 30$ & 17/10/201100:50 & 10 & 69495 & 38.5 \\
\hline Shelf winds & 01/01/2010 00:00 & 07/08/2011 21:00 & 60 & 13751 & 2.0 \\
\hline Local winds & $21 / 06 / 201015: 00$ & 14/06/2011 09:50 & 10 & 43232 & 16.1 \\
\hline Angles & 29/06/2010 11:00 & 17/10/2011 00:00 & 10 & 29872 & 0 \\
\hline \multicolumn{6}{|l|}{ Subseries } \\
\hline 1. Jul-10 & 29/06/10 11:00 & 23/07/10 10:00 & 10 & 3451 & 0 \\
\hline 2. Aug-10 & $24 / 07 / 1014: 00$ & 17/08/10 13:00 & 10 & 3451 & 0 \\
\hline 3. Mar-11 & $19 / 03 / 1115: 00$ & $12 / 04 / 1114: 00$ & 10 & 3451 & 0 \\
\hline 4. Apr-11 & $12 / 04 / 1115: 00$ & 06/05/11 14:00 & 10 & 3451 & 0 \\
\hline 5. May-11 & 06/05/11 15:00 & $30 / 05 / 1114: 00$ & 10 & 3451 & 0 \\
\hline
\end{tabular}


Table 2. Intra-raft tidal circulation. Speed of maximum tidal current $\left(\mathrm{M}_{2} ; \mathrm{cm} \mathrm{s}{ }^{-1}\right)$ and percentages of total variance explained by the tide (var; \%) in each side of the raft. Tide is assumed as the contribution of the constituents with significant amplitudes and signal to noise ratios $>2$ (Piedracoba et al., 2014). Only sides where the $M_{2}$ constituent was significant were reported.

\begin{tabular}{lcccccccc}
\hline \multirow{2}{*}{ Series } & \multicolumn{2}{c}{ Bow } & \multicolumn{2}{c}{ Stern } & \multicolumn{2}{c}{ Port } & \multicolumn{3}{c}{ Starboard } \\
\cline { 2 - 9 } & $\mathbf{M}_{2}$ & var & $\mathbf{M}_{2}$ & var & $\mathbf{M}_{2}$ & Var & $\mathbf{M}_{2}$ & var \\
\hline 1. Jul-10 & $2.9 \pm 0.6$ & 32 & $1.2 \pm 0.6$ & 11 & $0.5 \pm 0.3$ & 10 & $5.5 \pm 0.8$ & 56 \\
2. Aug-10 & $2.6 \pm 0.6$ & 21 & $1.3 \pm 0.6$ & 19 & $2.1 \pm 0.9$ & 24 & $4.0 \pm 0.6$ & 54 \\
3. Mar-11 & $1.0 \pm 0.5$ & 16 & $0.3 \pm 0.2$ & 12 & $0.6 \pm 0.6$ & 2 & $4.8 \pm 1.5$ & 27 \\
4. Apr-11 & $1.2 \pm 0.4$ & 17 & $0.6 \pm 0.4$ & 9 & $0.8 \pm 0.9$ & 3 & $7.9 \pm 1.5$ & 59 \\
5. May-11 & $1.8 \pm 1.3$ & 10 & $0.5 \pm 0.5$ & 2 & $0.9 \pm 0.8$ & 2 & $2.5 \pm 1.2$ & 14 \\
\hline
\end{tabular}


Table 3. Complex cross-correlations coefficients $(\mathrm{R})$ and phases $(\mathrm{Ph}$; degrees counter clockwise) between the subtidal flows at each side of the raft. Only significant correlations are presented. Two-tailed critical value of $\mathrm{R}$ for 113 degrees of freedom $(\mathrm{n}=3456)$ is 0.20 , for $\mathrm{p}=0.05(95 \%)$.

\begin{tabular}{|c|c|c|c|c|c|c|c|c|c|c|c|c|}
\hline \multirow{2}{*}{ Series } & \multicolumn{2}{|c|}{ Bow_Stern } & \multicolumn{2}{|c|}{ Bow_Port } & \multicolumn{2}{|c|}{ Bow_Starb. } & \multicolumn{2}{|c|}{ Stern_Port } & \multicolumn{2}{|c|}{ Stern_Starb. } & \multicolumn{2}{|c|}{ Port_Starb. } \\
\hline & $\mathbf{R}$ & $\mathbf{P h}$ & $\mathbf{R}$ & $\mathbf{P h}$ & $\mathbf{R}$ & $\mathbf{P h}$ & $\mathbf{R}$ & $\mathbf{P h}$ & $\mathbf{R}$ & $\mathbf{P h}$ & $\mathbf{R}$ & $\mathbf{P h}$ \\
\hline 1. Jul-10 & 0.44 & 131 & 0.42 & 156 & 0.92 & 197 & 0.29 & 331 & 0.50 & 51 & 0.56 & 43 \\
\hline 2. Aug-10 & 0.81 & 49 & 0.83 & 134 & 0.38 & 129 & 0.57 & 89 & 0.30 & 28 & 0.62 & 29 \\
\hline 3. Mar-11 & 0.36 & 28 & 0.28 & 232 & 0.62 & 119 & 0.22 & 195 & 0.52 & 20 & 0.34 & 236 \\
\hline 4. Apr-11 & 0.25 & 69 & 0.33 & 352 & 0.27 & 211 & 0.23 & 246 & 0.59 & 131 & 0.68 & 248 \\
\hline 5. May-11 & - & - & 0.24 & 239 & 0.24 & 134 & 0.20 & 198 & 0.49 & 162 & 0.47 & 290 \\
\hline
\end{tabular}


Table 4. Complex cross correlations coefficients (R) and phases (Ph; degrees CCW) between shelf winds (W), river discharge (Q) and the raft water net transport. Only significant correlations are presented. Two-tailed critical values of $\mathrm{R}$ for 17 degrees of freedom $(\mathrm{W} ; \mathrm{n}=576)$ and for 24 degrees of freedom $(\mathrm{Q} ; \mathrm{n}=24)$ are 0.46 and 0.39 for $\mathrm{p}=$ $0.05(95 \%)$, respectively.

\begin{tabular}{lcccc}
\hline & \multicolumn{2}{c}{ W } & \multicolumn{2}{c}{ Q } \\
\hline & R & Ph & R & Ph \\
\hline 1. Jul-10 & 0.50 & 338 & 0.87 & 180 \\
2. Aug-10 & 0.79 & 322 & 0.67 & 180 \\
3. Mar-11 & - & - & 0.85 & 180 \\
4. Apr-11 & 0.72 & 318 & 0.94 & 180 \\
5. May-11 & 0.71 & 322 & 0.81 & 180 \\
\hline
\end{tabular}


Table 5. Comparison between the displacement of the raft (translational and rotational velocities) and the water flows measured through each side of raft P46 (modulus of the velocity in each side). [P25, P75]: values in $\mathrm{cm} \mathrm{s}^{-1}$ delimiting the $25 \%$ and $75 \%$ percentiles of each variable. Rotational velocity of the raft $\left(\right.$ degrees $\left.\min ^{-1}\right)$ has been converted to $\mathrm{cm} \mathrm{s}^{-}$ ${ }^{1}$ (assuming the raft as a circle of $11 \mathrm{~m}$ radius) to compare with the other velocities.

\begin{tabular}{lcccccc}
\hline Series & $\begin{array}{c}\text { Translational } \\
\text { velocity }\end{array}$ & $\begin{array}{c}\text { Rotational } \\
\text { velocity }\end{array}$ & Bow & Stern & Port & Starboard \\
\hline 1. Jul-10 & {$[0.14,0.41]$} & {$[0.08,0.35]$} & {$[1.8,4.3]$} & {$[1.3,3.3]$} & {$[1.2,3.0]$} & {$[5.7,6.5]$} \\
2. Aug-10 & {$[0.14,0.41]$} & {$[0.07,0.33]$} & {$[2.2,5.4]$} & {$[1.4,3.2]$} & {$[1.8,5.1]$} & {$[4.5,4.9]$} \\
3. Mar-11 & {$[0.14,0.54]$} & {$[0.06,0.33]$} & {$[2.4,4.1]$} & {$[1.0,2.1]$} & {$[1.1,3.0]$} & {$[5.3,9.2]$} \\
4. Apr-11 & {$[0.14,0.41]$} & {$[0.07,0.34]$} & {$[1.6,4.0]$} & {$[1.0,2.2]$} & {$[1.4,3.9]$} & {$[7.9,12]$} \\
5. May-11 & {$[0.14,0.41]$} & {$[0.06,0.28]$} & {$[2.6,5.9]$} & {$[1.7,4.2]$} & {$[2.0,5.0]$} & {$[4.2,9.0]$} \\
\hline
\end{tabular}


Table 6. Displacement of the raft and forcing agents: tide and winds; tide_pos/or (\%), variability of the position/orientation time series explained by the tide. Tide was obtained from harmonic analysis, using t tide code and choosing the components with $\mathrm{SNR}>2 . \sigma_{\text {res }} / \varepsilon_{\text {instr }}$, where $\sigma_{\mathrm{res}}$ is the standard deviation of the residuals of the position time series/orientation time series and $\varepsilon_{\mathrm{instr}}$, is: $\varepsilon_{\mathrm{GPS}}= \pm 2.5 \mathrm{~m}$ and $\varepsilon_{\mathrm{compass}}=$ $\pm 2^{\circ}(\sim 22 \mathrm{~m})$. Complex cross-correlations coefficients $(\mathrm{R})$ and phases ( $\mathrm{Ph}$; degrees counter clockwise) between: Local and shelf winds; Local/Shelf winds and the residuals of the tide obtained from position/orientation time series. $\left(* * \mathrm{n}=3456 ; *^{*}=576\right)$. Two-tailed critical values of $\mathrm{R}$ for 17 degrees of freedom $\left({ }^{*} \mathrm{n}=576\right)$ and for 113 degrees of freedom $(* * n=3456)$ are 0.46 and 0.20 for $p=0.05(95 \%)$, respectively.

\begin{tabular}{|c|c|c|c|c|c|c|c|c|c|c|c|c|c|c|c|c|}
\hline \multirow{3}{*}{ Series } & \multirow{3}{*}{$\begin{array}{l}\text { tide } \\
\text { pos } \\
(\%)\end{array}$} & \multirow{3}{*}{$\begin{array}{l}\text { tide } \\
\text { or } \\
(\%)\end{array}$} & \multirow{3}{*}{$\begin{array}{c}\sigma \\
\text { res_pos } \\
\text { (m) }\end{array}$} & \multirow{3}{*}{$\begin{array}{c}\text { Pos } \\
\sigma_{\text {res }} / \varepsilon_{\text {GPS }}\end{array}$} & \multirow{3}{*}{$\begin{array}{c}\sigma \\
\text { res_or } \\
(\bar{m})\end{array}$} & \multirow{3}{*}{$\begin{array}{c}\text { Or } \\
\sigma_{\text {res }} / \varepsilon_{\text {compass }}\end{array}$} & \multirow{2}{*}{\multicolumn{2}{|c|}{$\begin{array}{l}\text { Local vs. Shelf } \\
\text { Winds }\end{array}$}} & \multicolumn{4}{|c|}{ Position residuals } & \multicolumn{4}{|c|}{ Orientation residuals } \\
\hline & & & & & & & & & \multicolumn{2}{|c|}{ Local** } & \multicolumn{2}{|c|}{ Shelf* } & \multicolumn{2}{|c|}{ Local** } & \multicolumn{2}{|c|}{ Shelf* } \\
\hline & & & & & & & $\mathbf{R}$ & $\mathbf{P h}$ & $\mathbf{R}$ & $\mathbf{P h}$ & $\mathbf{R}$ & $\mathbf{P h}$ & $\mathbf{R}$ & $\mathbf{P h}$ & $\mathbf{R}$ & $\mathbf{P h}$ \\
\hline 1. Jul-10 & 54.6 & 59.6 & 7.5 & 3.0 & 6.7 & 0.3 & 0.83 & 12 & 0.52 & 135 & - & - & 0.33 & 9 & - & - \\
\hline 2. Aug-10 & 65.6 & 69.9 & 5.3 & 2.1 & 5.5 & 0.2 & 0.97 & 13 & 0.63 & 81 & 0.60 & 65 & 0.69 & 352 & 0.67 & 338 \\
\hline 3. Mar-11 & 66.2 & 58.0 & 6.6 & 2.6 & 7.0 & 0.3 & 0.86 & 12 & - & - & - & - & 0.37 & 8 & - & - \\
\hline 4. Apr-11 & 72.4 & 67.9 & 5.8 & 2.3 & 5.9 & 0.3 & 0.92 & 15 & 0.51 & 262 & 0.59 & 241 & 0.42 & 340 & - & - \\
\hline 5. May-11 & 19.4 & 21.8 & 7.2 & 2.9 & 8.8 & 0.4 & 0.93 & 4 & 0.58 & 207 & 0.56 & 199 & 0.69 & 350 & 0.62 & 345 \\
\hline
\end{tabular}




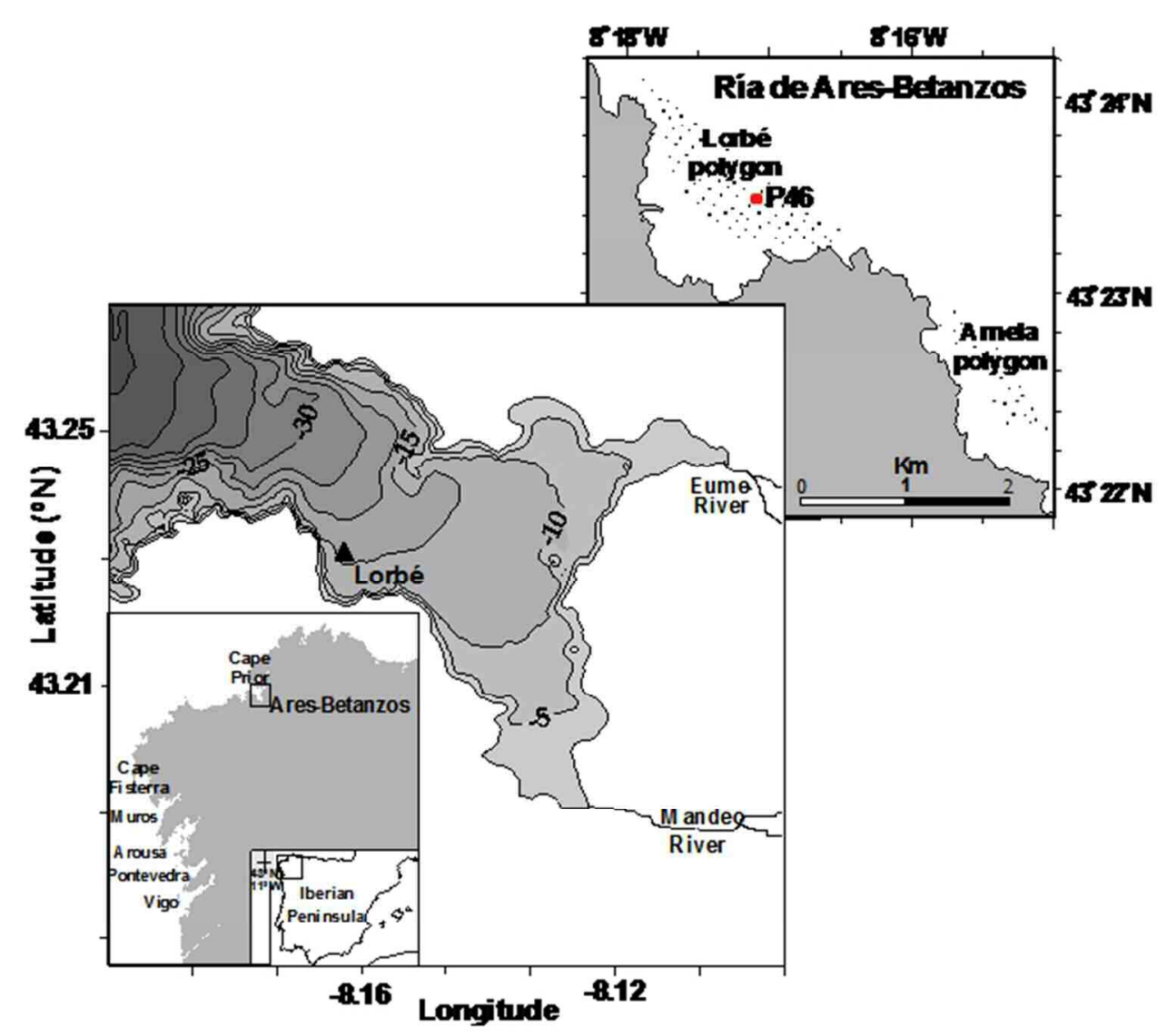

Figure 1 Study area: Ría de Ares-Betanzos (NW Spain), location of Lorbé polygon (black triangle), and the position of P46 raft inside the polygon (red circle). In the zoom also appears the near polygon of Arnela. $176 \times 152 \mathrm{~mm}(96 \times 96 \mathrm{DPI})$ 


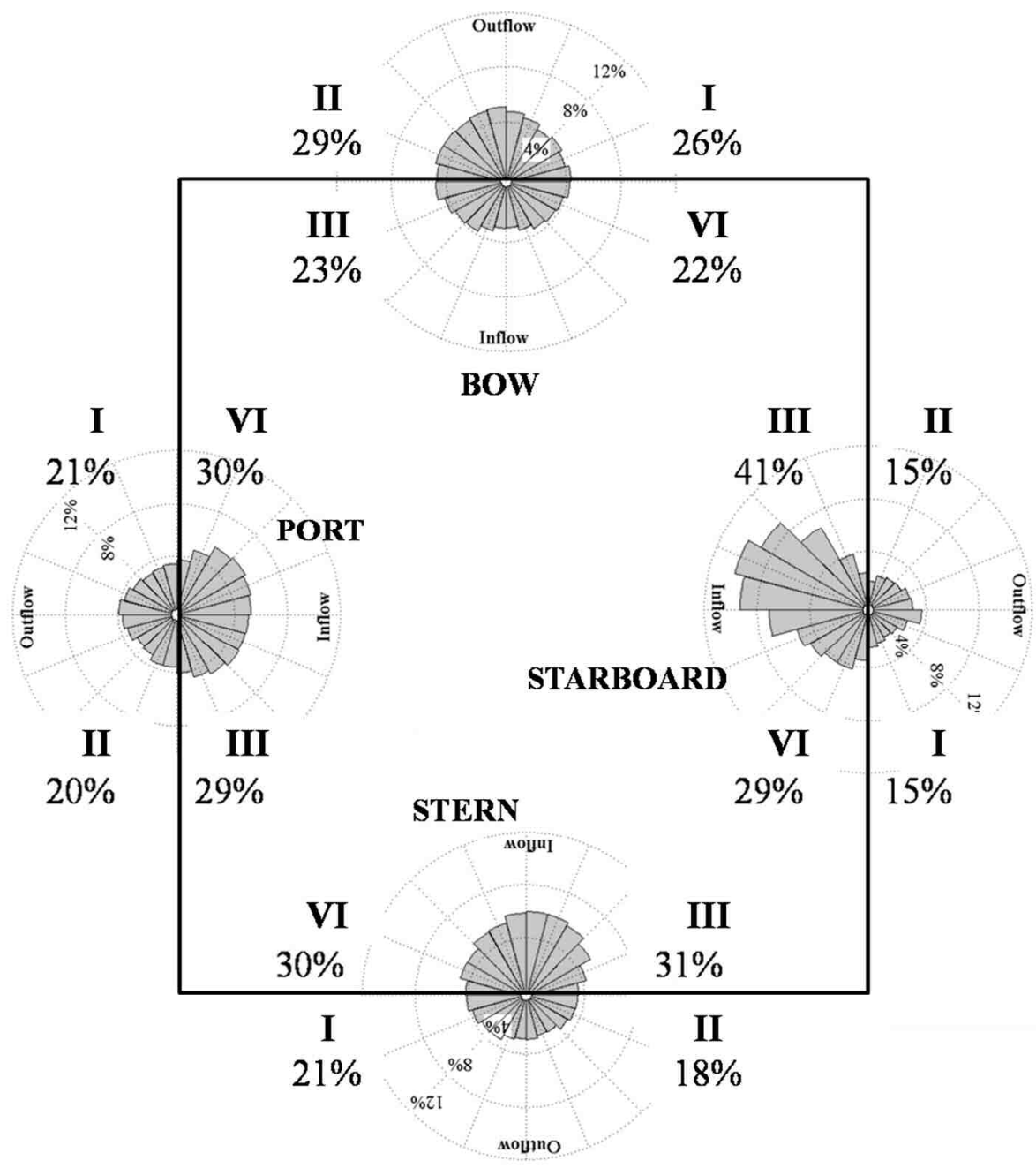

Figure 2 Main directions of water flows entering at each side of the raft $(n=29872)$. $197 \times 220 \mathrm{~mm}(150 \times 150$ DPI $)$ 

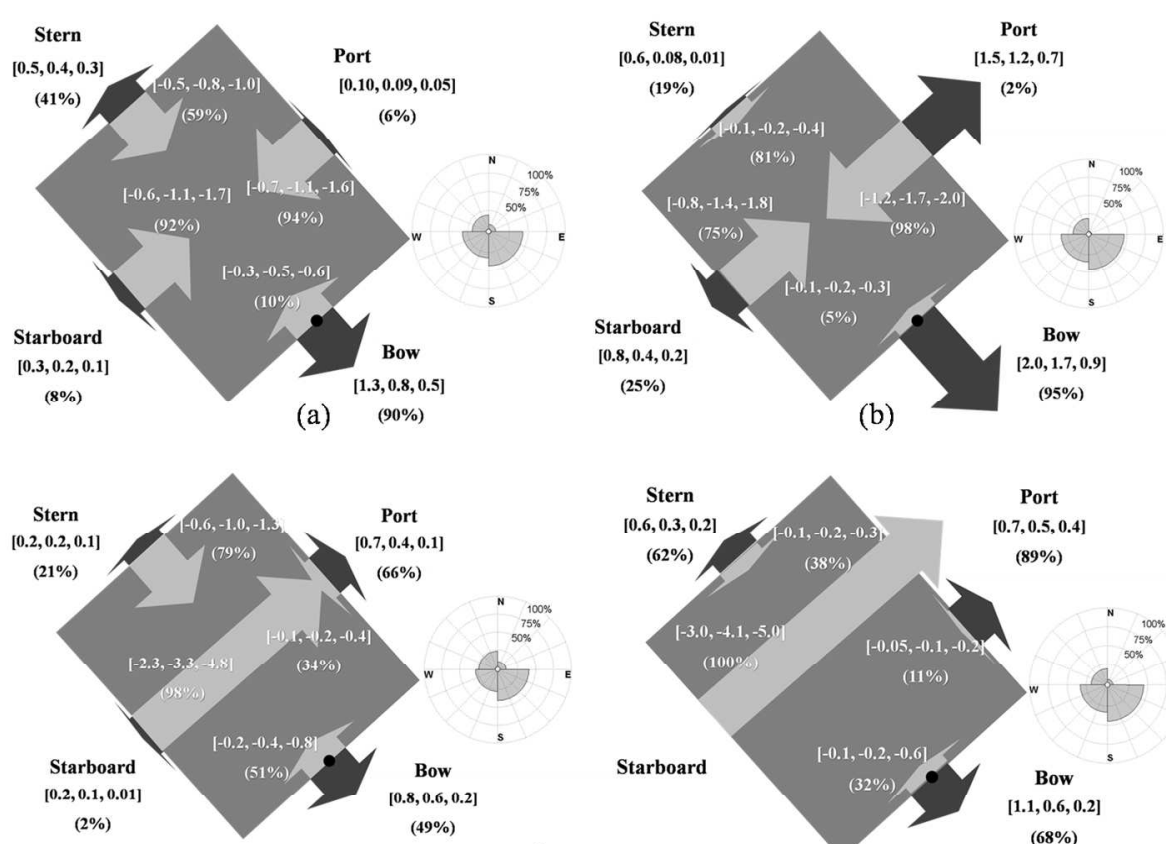

(b)

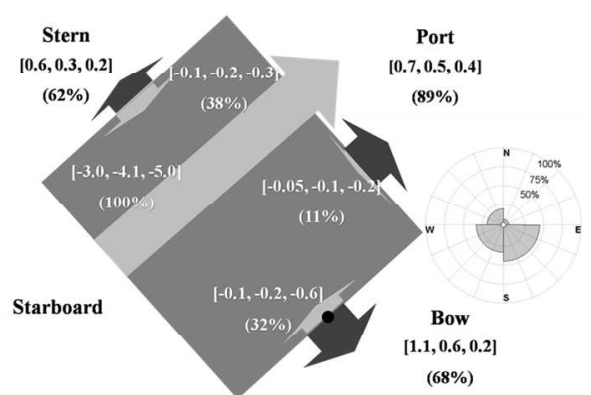

(c)

(d)

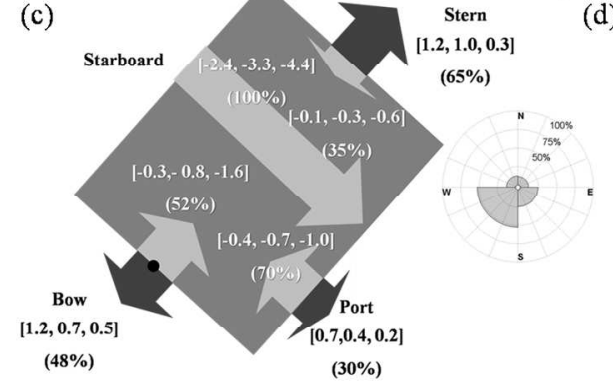

(e)

Figure 3 Fluxes at each side of the raft during July 2010 (a), August 2010 (b), March 2011 (c), April 2011 (d), May 2011 (e).Velocity percentiles for outflows (black)/inflows (white) ([P25, P50, P75]) and outflow/inflow percents of time during the 24 days. Arrows are scaled. Black arrows: outflow> 0; Gray arrows: inflow $<0$. Black circle denotes the most probable position of the bow during each period. Orientation rose shows the most probable orientation of the bow of the raft during the sampled period. $445 \times 447 \mathrm{~mm}$ (96 x 96 DPI) 


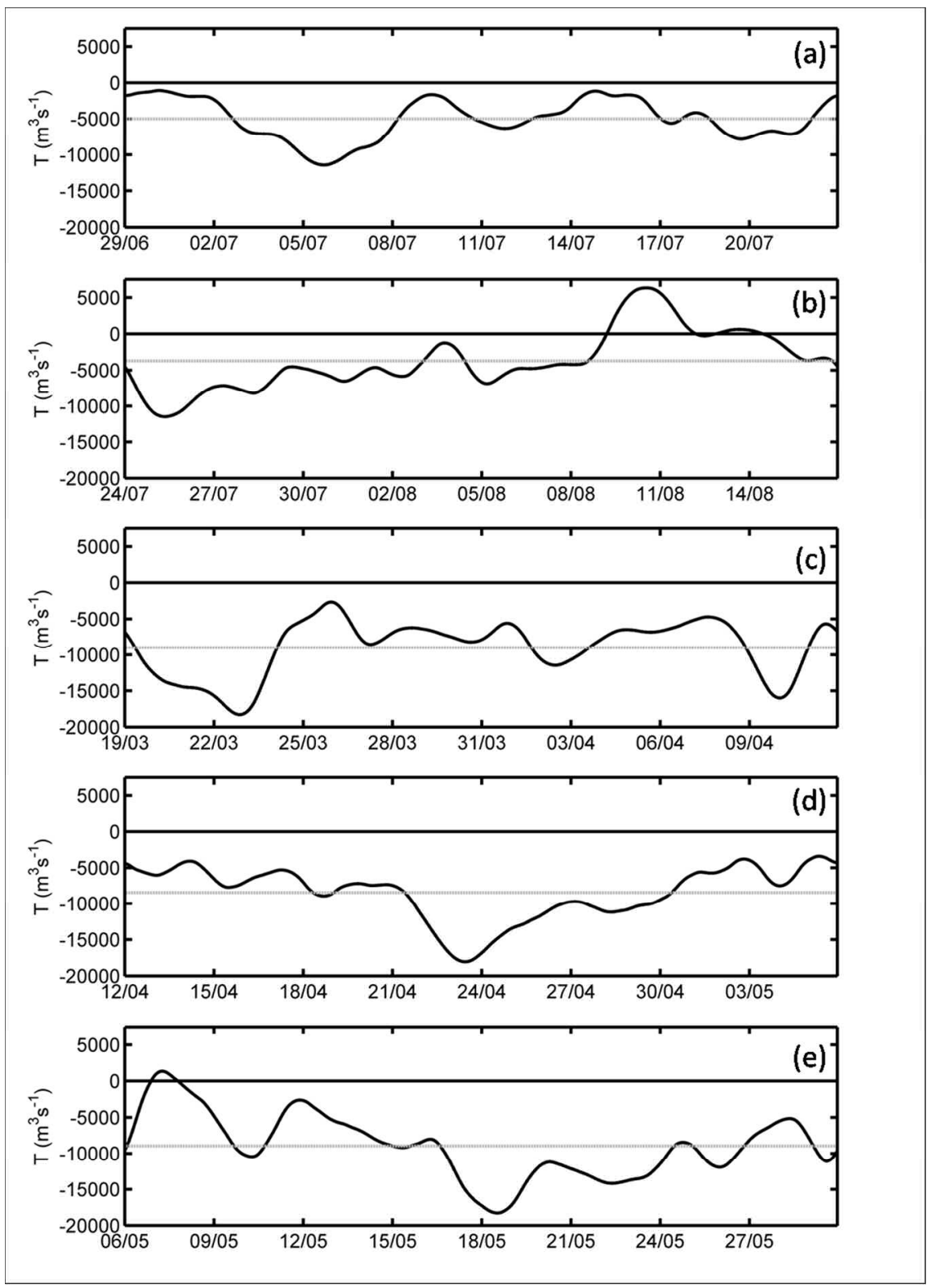

Figure 4 Net water volume transported inside $(T<0)$ /outside $(T>0)$ the raft during July 2010 (a), August 2010 (b), March 2011 (c), April 2011 (d) and May 2011 (e). Grey line denotes the 24-day average of the net water volume transported.

$190 \times 264 \mathrm{~mm}(150 \times 150 \mathrm{DPI})$ 


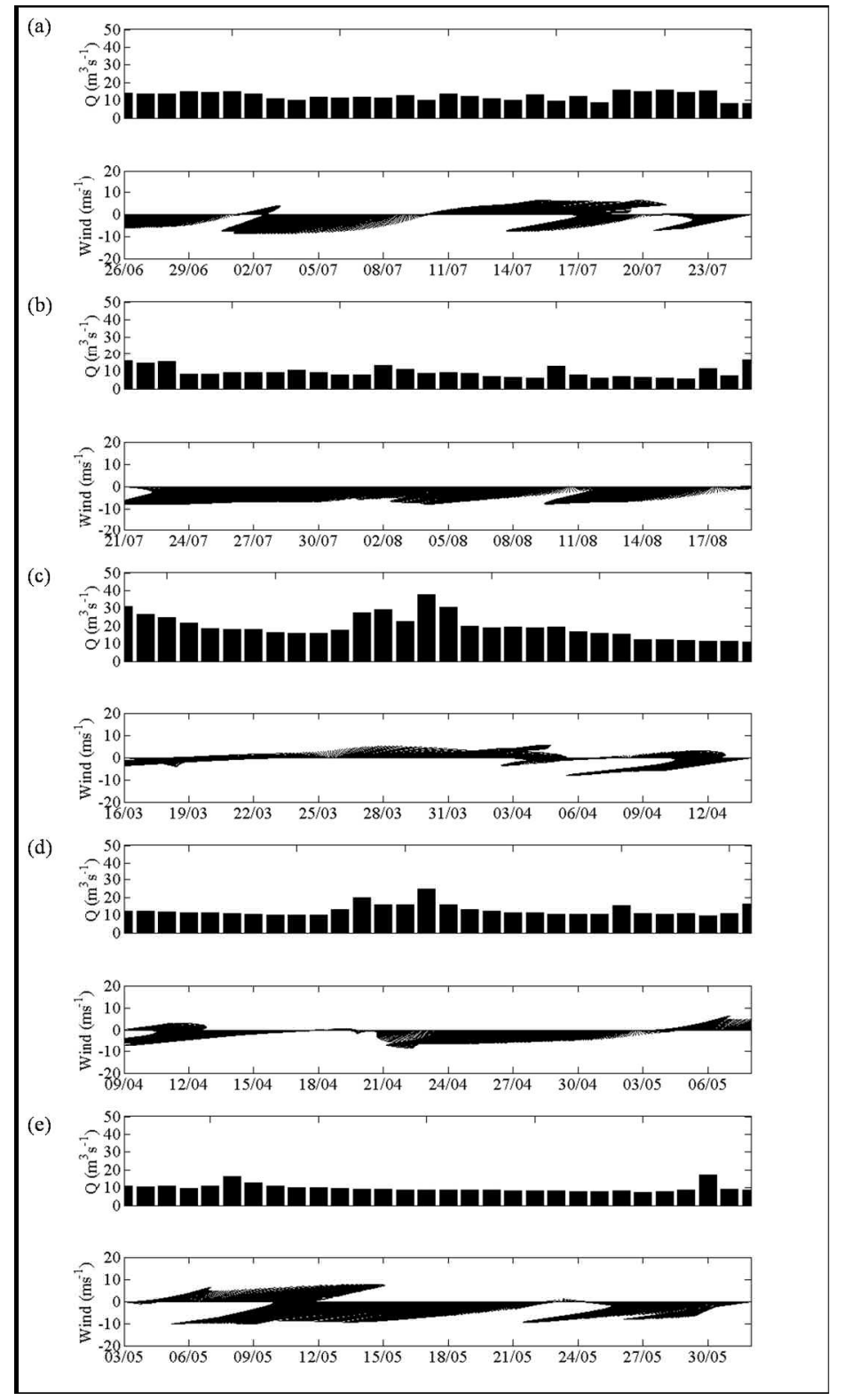

Figure 5 Environmental conditions in the study area during July 2010 (a), August 2010 (b), March 2011 (c), April 2011 (d) and May 2011 (e). Rivers discharge (Q) and Vilano residual wind (W). $255 \times 435 \mathrm{~mm}(150 \times 150 \mathrm{DPI})$ 


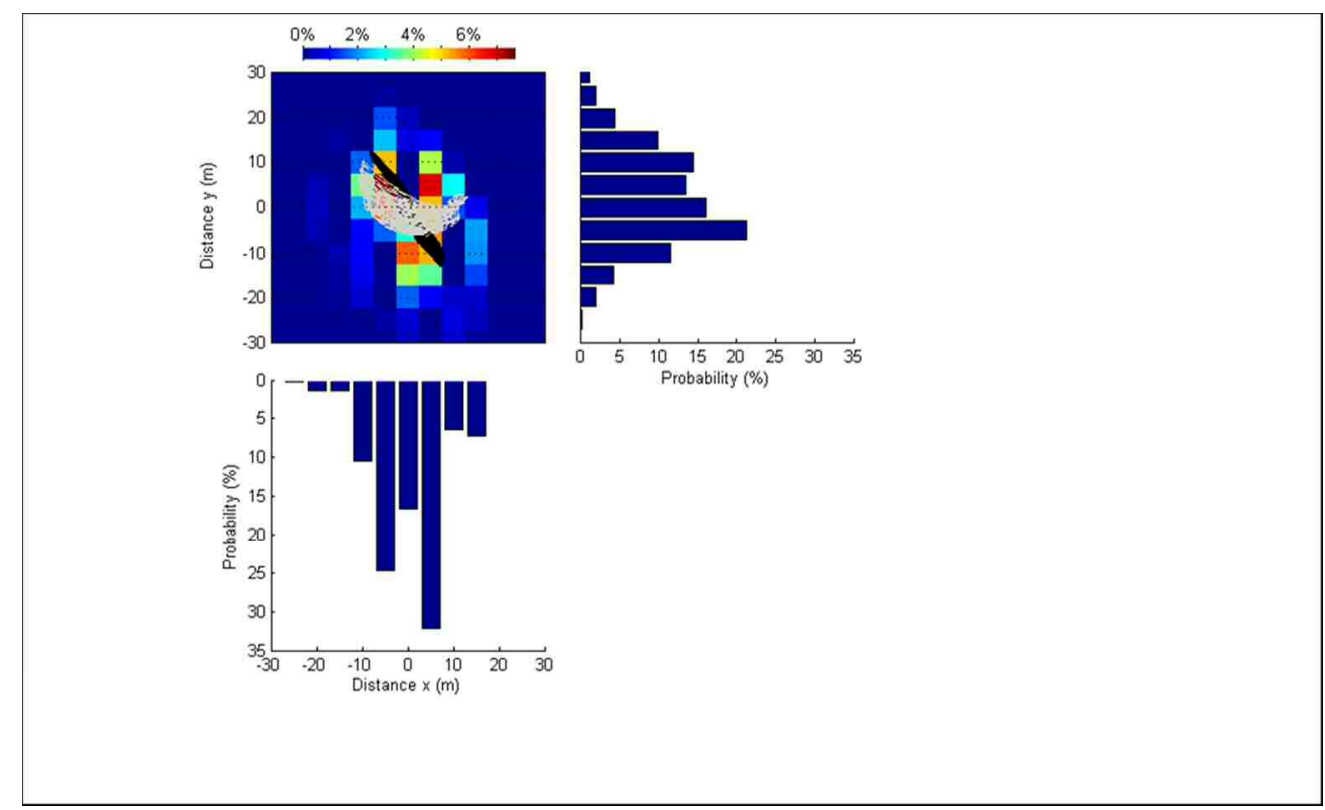

Figure 6 Clearance area of raft P46 from 29/06/2010 10:44 to 14/06/2011 09:44, $n=40967$. Tidal signals obtained from the position (black) and the orientation (grey) time series (section 3.3) were superimposed to the area of most probable positions. Accumulated probabilities in the $x$ - and $y$-axis are also shown.

$173 \times 105 \mathrm{~mm}(150 \times 150 \mathrm{DPI})$ 
Page 39 of 43

Reviews in Aquaculture

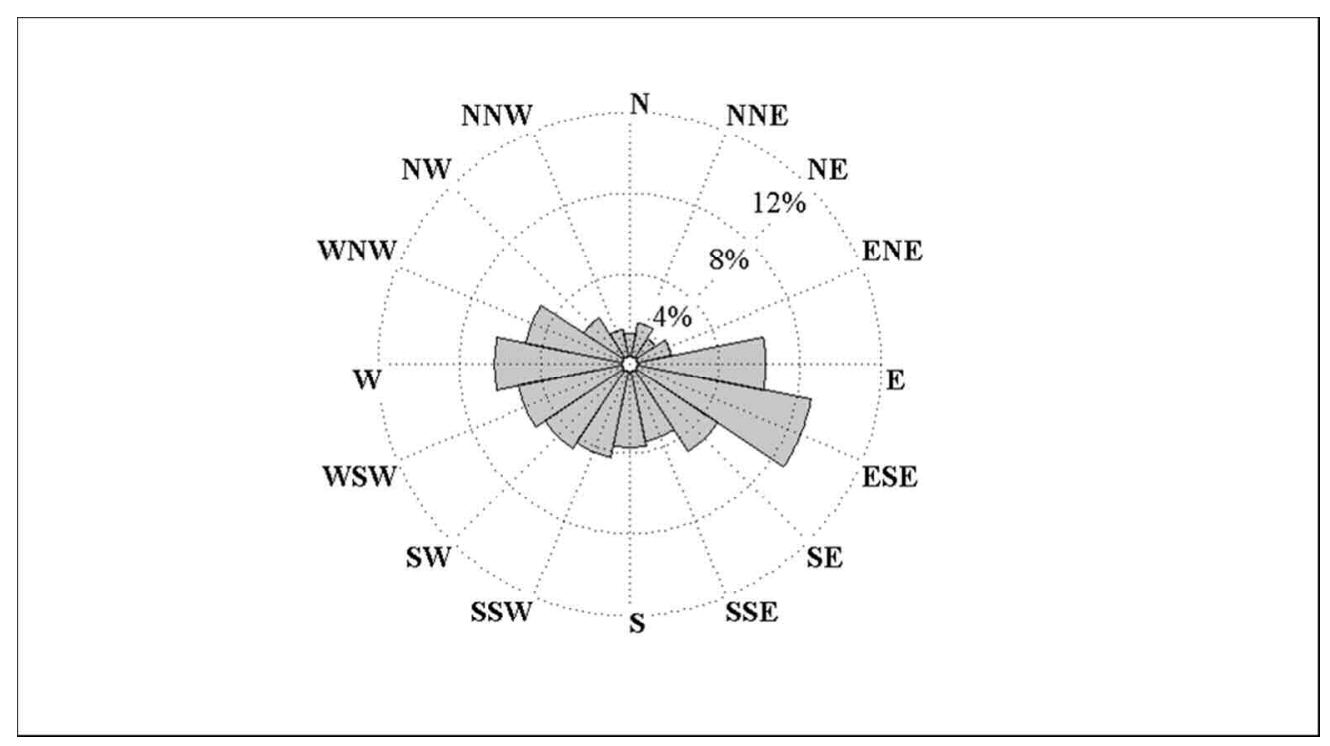

Figure 7 Orientation of the bow of raft P46 during the sampling period $(n=69495)$.

$189 \times 104 \mathrm{~mm}(137 \times 137 \mathrm{DPI})$ 
(a)

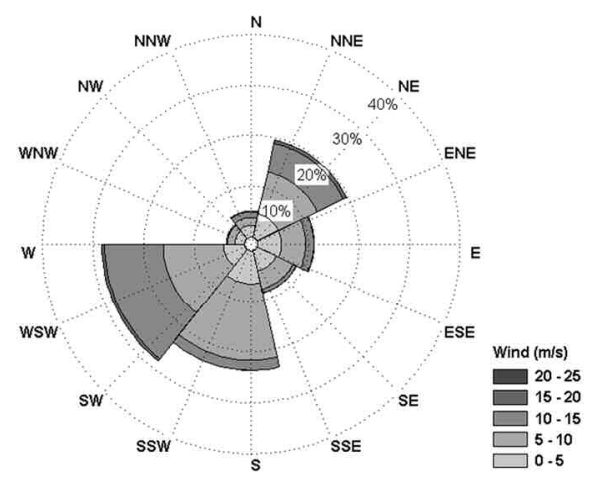

(b)

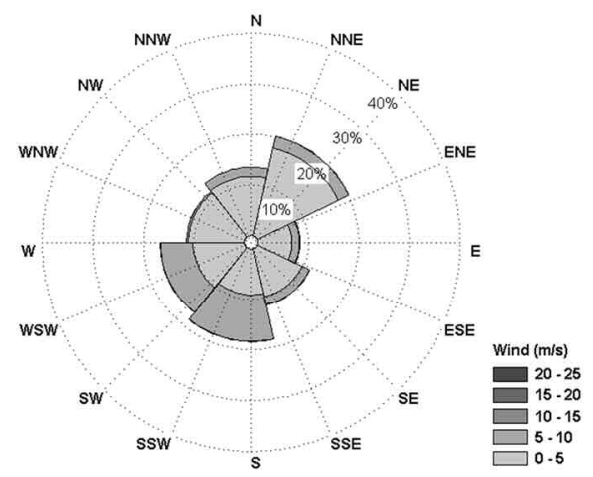

(c)

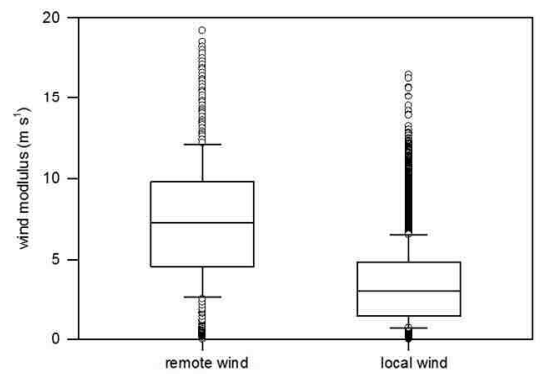

Figure 8 Rose of (a) shelf and (b) local winds and (c) Box-whisker plot of the shelf and local wind celerity. On each box, the central mark is the median, the edges of the box are the 25th and 75th percentiles, the whiskers extend to the most extreme data points not considered outliers, and outliers are plotted individually

$339 \times 549 \mathrm{~mm}(96 \times 96$ DPI) 


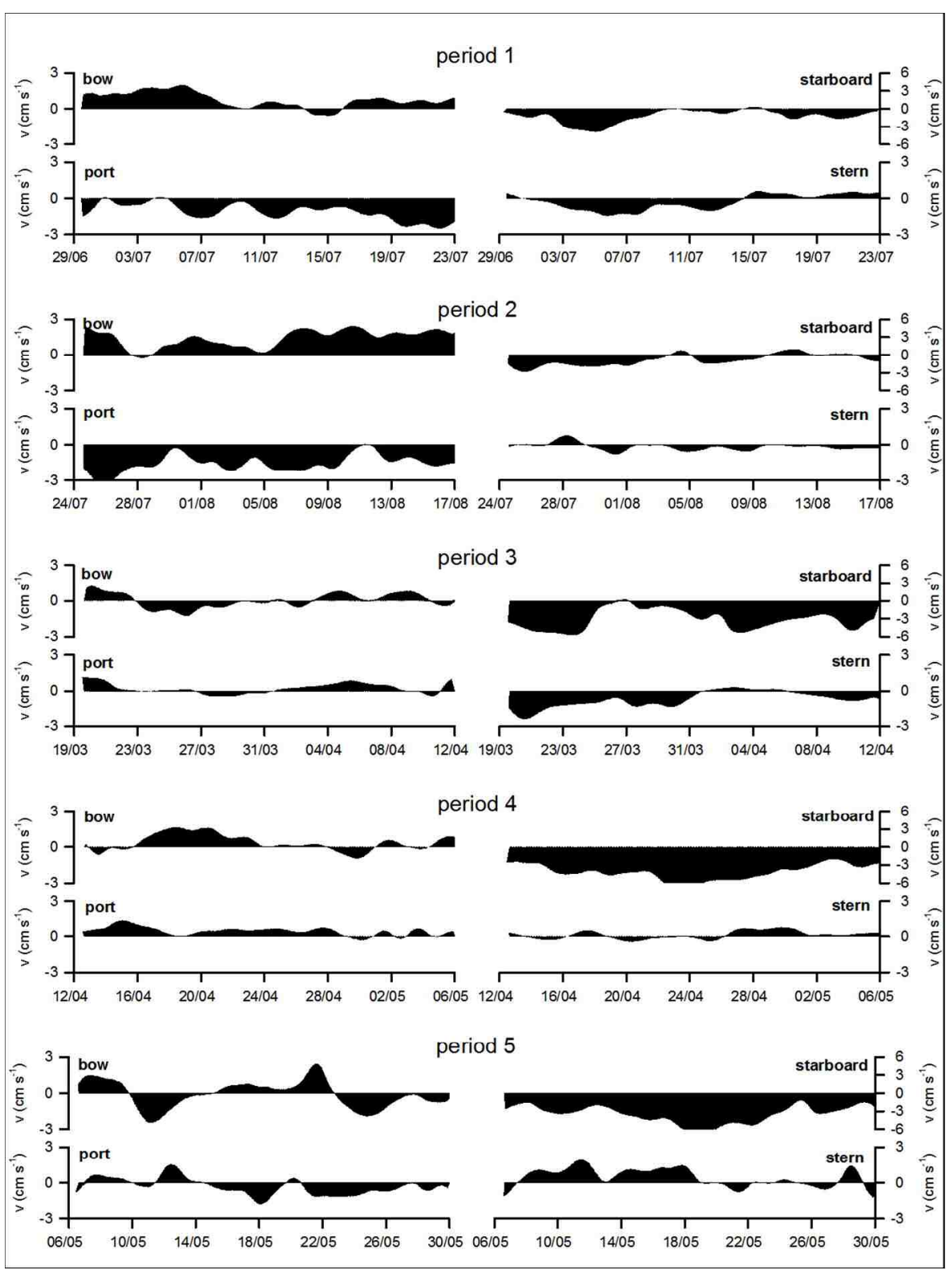

Appendix I: Time series of subtidal current velocity data at each side of the raft for the five studied periods: period 1: July 2010, period 2: August 2010, period 3: March 2011, period 4: April 2011 and period 5: May 2011. Positive/negative values denote outflows/inflows. 


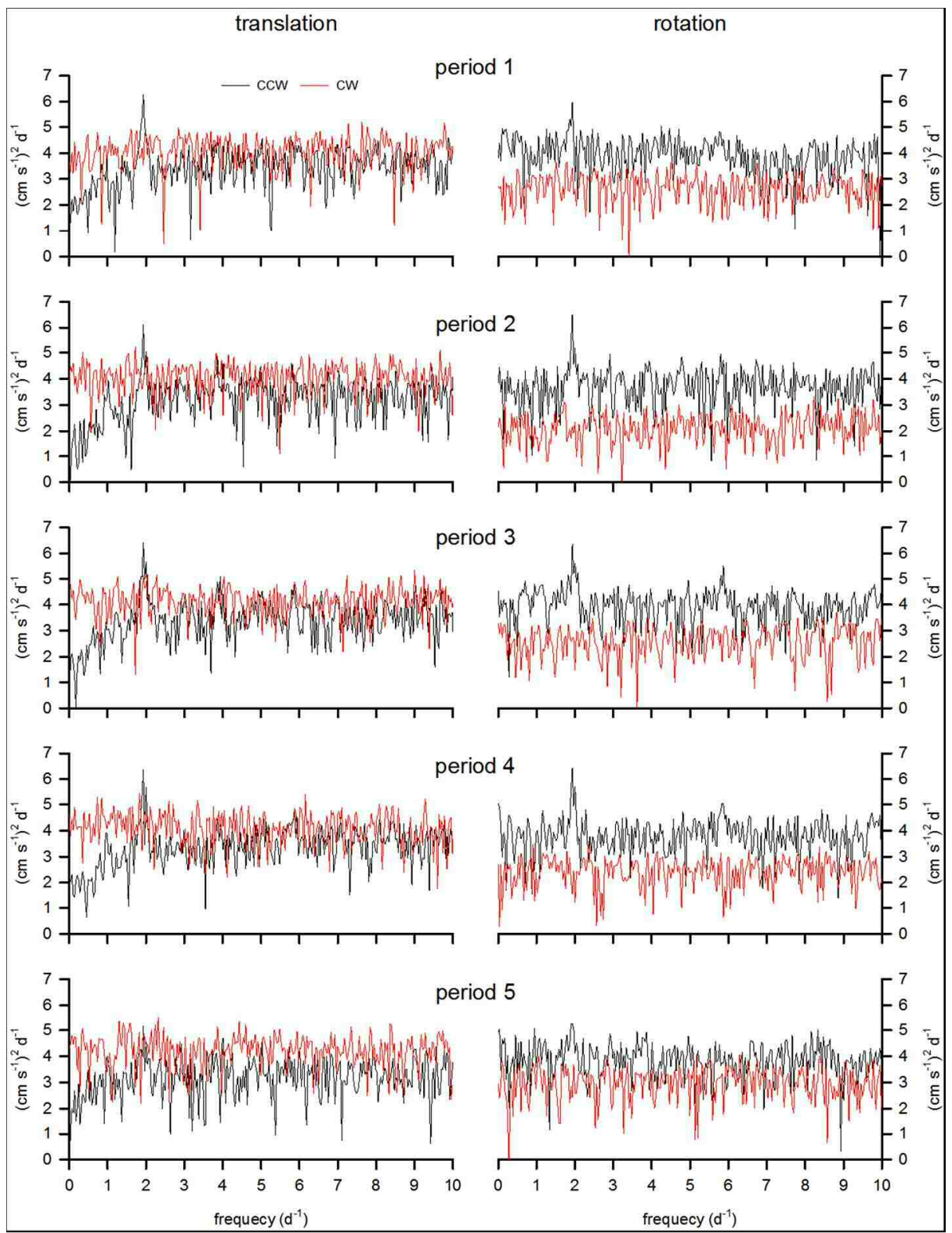

Appendix II: Counter-clockwise (CCW, black) and clockwise (CW, red) components of the Fast Fourier Transform of raft translational and rotational velocities. Frequency in day-1 (d-1). $208 \times 271 \mathrm{~mm}(150 \times 150 \mathrm{DPI})$ 

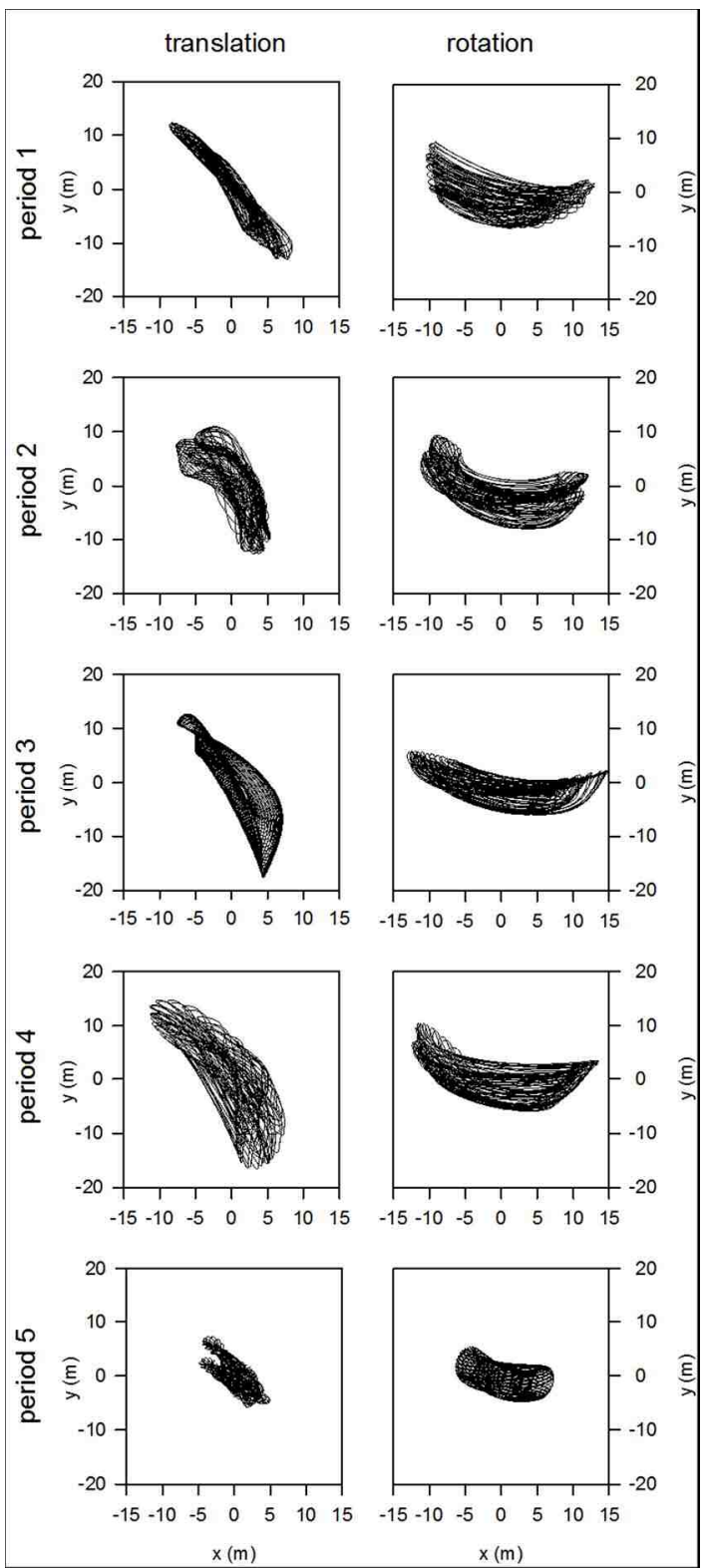

Appendix III Tidal signal obtained from the harmonic analysis applied to the position (translation) and orientation (rotation) time series. The tidal components used in each harmonic analysis were chosen following SNR criteria > 2 (Pawlowicz et al., 2002). $128 \times 289 \mathrm{~mm}(150 \times 150 \mathrm{DPI})$ 